\title{
Oral toxicity of arjunolic acid on hematological, biochemical and histopathological investigations in female Sprague Dawley rats
}

\author{
Khurram Aamir ${ }^{1}$, Hidayat Ullah Khan ${ }^{1}$, Chowdhury Faiz Hossain ${ }^{2}$, Mst. Rejina Afrin ${ }^{2}$, Imam Shaik ${ }^{3}$, Naguib \\ Salleh $^{4}$, Nelli Giribabu ${ }^{4}$, Aditya Arya ${ }^{\text {Corresp. 5, 6, } 7}$ \\ ${ }^{1}$ School of Pharmacy, Faculty of Health and Medical Sciences, Taylor's University, Subang Jaya, Malaysia \\ 2 Department of Pharmacy, Faculty of Science and Engineering, East West University, Dhaka, Bangladesh \\ 3 Department of Pathology, School of Medicine, Faculty of Health and Medical Sciences, Taylor's University, Subang Jaya, Malaysia \\ 4 Department of Physiology, Faculty of Medicine, University of Malaya, Kuala Lumpur, Malaysia \\ 5 Department of Pharmacology and Therapeutics, School of Medicine, Faculty of Health and Medical Sciences, Taylor's University, Subang Jaya, Malaysia \\ 6 Department of Pharmacology and Therapeutics, Faculty of Medicine, Dentistry and Health Sciences, University of Melbourne, Melbourne, Parkville, VIC, \\ Australia \\ 7 Malaysian Institute of Pharmaceuticals and Nutraceuticals (IPHARM), Bukit Gambir, Gelugor, Pulau Pinang, Malaysia \\ Corresponding Author: Aditya Arya \\ Email address: aditya.arya@taylors.edu.my
}

Background. Arjunolic acid (AA) is a potent phytochemical with wider pharmacological activities. Despite potential medicinal properties on various in vitro and in vivo studies, there is still a dearth of scientific data related to its safety profile and toxicological parameters. The current study aimed to investigate acute toxicity of AA in normal female Sprague Dawley (SD) rats. Methods. In this study, AA was administered orally at an individual dose of $300 \mathrm{mg} / \mathrm{kg}$ and $2000 \mathrm{mg} / \mathrm{kg}$ body weight to group 1 and 2 respectively, while group 3 served as normal control. All the animals were observed for two weeks to determine any behavioral and physical changes. On day fifteen, blood was collected for hematological and biochemical investigation, later animals from all the three groups were euthanized to harvest and store essential organs for histopathological analysis. Four different staining techniques; hematoxylin and eosin (H\&E), Masson trichrome (MT), Periodic acid Schiff (PAS) and Oil O Red were used to investigate any alterations in different tissues through microscopical observation. Results. Result of the study showed no morbidity and mortality at two different dosage of AA treatment. Daily food \& water intake, body weight, relative organ weight, hematological and biochemical parameters were detected to be normal with no severe alteration seen through microscopical investigation in the structure of harvested tissues. Our finding support safety profile of AA which was well tolerated at higher dose, thus, warrants in-detail study on subacute disease model. 


\section{Oral toxicity of arjunolic acid on hematological, biochemical and 2 histopathological investigations in female Sprague Dawley rats}

3

4 Khurram Aamir ${ }^{1}$, Hidayat Ullah Khan ${ }^{1}$, Chowdhury Faiz Hossain ${ }^{2}$, Mst. Rejina Afrin ${ }^{2}$, Imam

5 Shaik $^{3}$, Naguib Salleh ${ }^{4}$, Nelli Giribabu ${ }^{4}$, Aditya Arya ${ }^{5,6,7^{*}}$

6

7

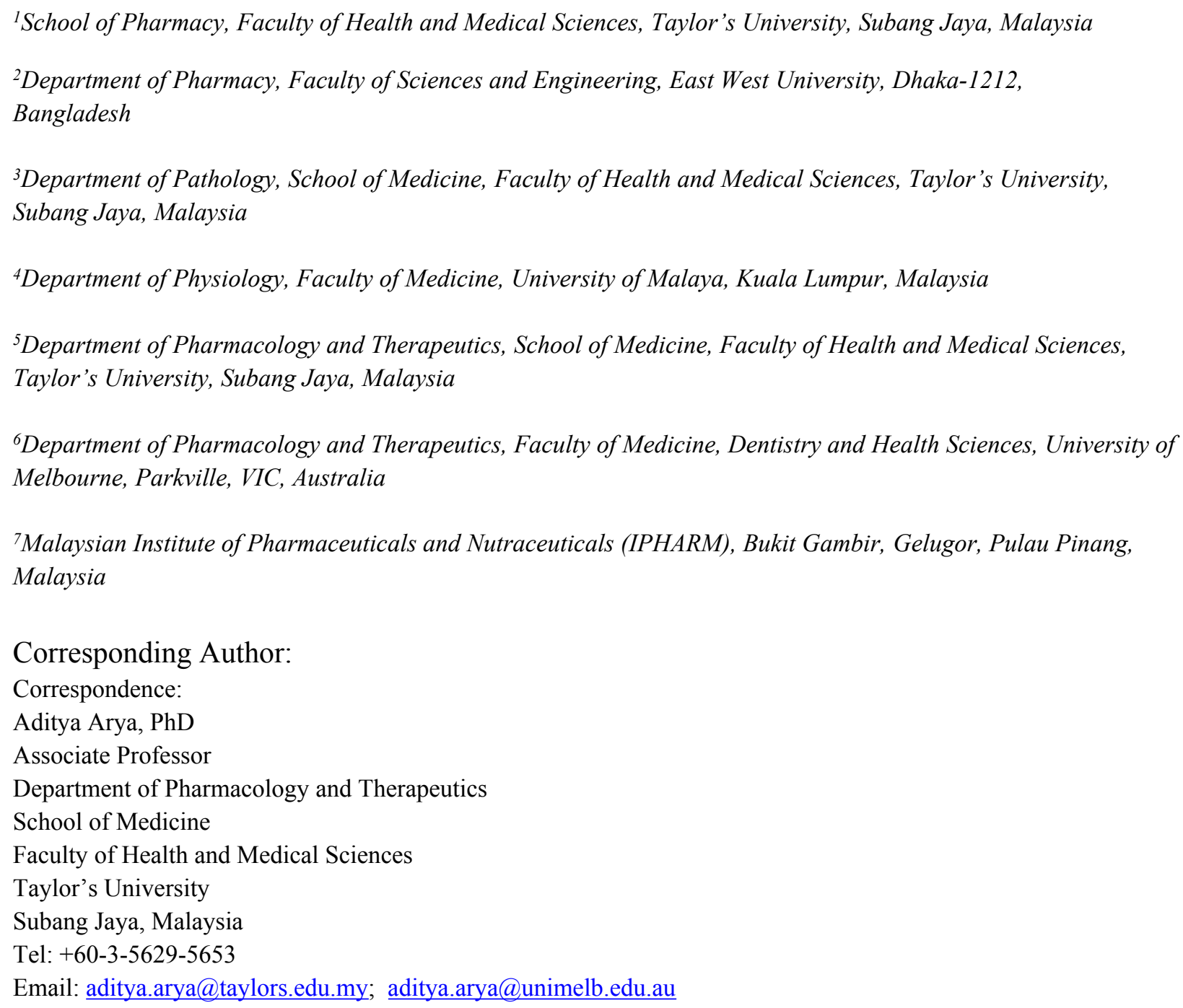


43

44

45

46

47

48

49

50

51

52

53

54

55

56

57

58

59

60

61

62

63

64

65

66

67

\section{Abstract}

Background. Arjunolic acid (AA) is a potent phytochemical with wider pharmacological activities. Despite potential medicinal properties on various in vitro and in vivo studies, there is still a dearth of scientific data related to its safety profile and toxicological parameters. The current study aimed to investigate acute toxicity of AA in normal female Sprague Dawley (SD) rats.

Methods. In this study, AA was administered orally at an individual dose of $300 \mathrm{mg} / \mathrm{kg}$ and 2000 $\mathrm{mg} / \mathrm{kg}$ body weight to group 1 and 2 respectively, while group 3 served as normal control. All the animals were observed for two weeks to determine any behavioral and physical changes. On day fifteen, blood was collected for hematological and biochemical investigation, later animals from all the three groups were euthanized to harvest and store essential organs for histopathological analysis. Four different staining techniques; hematoxylin and eosin (H\&E), Masson trichrome (MT), Periodic acid Schiff (PAS) and Oil O Red were used to investigate any alterations in different tissues through microscopical observation.

Results. Result of the study showed no morbidity and mortality at two different dosage of AA treatment. Daily food \& water intake, body weight, relative organ weight, hematological and biochemical parameters were detected to be normal with no severe alteration seen through microscopical investigation in the structure of harvested tissues. Our finding support safety profile of AA which was well tolerated at higher dose, thus, warrants in-detail study on subacute disease model.

Keywords: Arjunolic acid; acute oral toxicity; hematological; biochemical parameters,

4 histopathology

\section{Introduction}


68

Nature has provided many therapeutic agents which are hidden in different forms in natural habitat. Essential compounds from marine, animal and plant sources play pivotal role in the prevention and management of various diseases. The initial concept of utilizing food as a source of medicine seems to be of great values after intensive research in the field of ethnopharmacology. Management plans and strategies using phytochemicals and medicinal plants are traditional way of treating various disorders among local communities of the past. Interestingly, usage of herbs and phytochemicals are in practice under Western Herbal Medicine, in Indian System of Medicine (ISM) such as Ayurvedic, Unani, Siddha, Homeopathic and in Traditional Chinese Medicine (TCM) (Pariyani et al. 2015).

In the recent years more focus is appeared on the treatment of numerous clinical conditions with nutraceuticals and dietary supplements including herbal medicines. Investigation of various plant extracts and their isolated phytocompounds and botanicals are of great attention among researchers. The use of natural products has developed more interest and confidence due to their safety and efficacy among people of all age groups (Amos et al. 2015). However, there is a lack of scientific data on the evidence based platform as well as toxicological investigations of these natural medicines (Yang et al. 2019). The toxicological information and safety profile of new compounds is of prime value, enabling us to choose an appropriate dosage in animal studies at preclinical level. These findings may be applicable further on humans at later stages of clinical trials (Thelingwani \& Masimirembwa 2014).

Bark of Terminalia arjuna tree from the family of Combretaceae is regarded as the wellknown herb from centuries in Ayurvedic system of medicine. The whole plant is a rich source of various active ingredients which are classified as saponins, ellagic acid, tannins, triterpenoid saponin, oligomeric proanthocyanidins, flavonoids, gallic acid and phytosterols (Ghosh et al. 
91 2010b). The triterpene saponins which comprises of arjunolic acid, arjungenin, arjunic acid, 92 and flavonoids including arjunolone, arjunone and luteolin are of great medicinal value 93 (Facundo et al. 2005; Ghosh et al. 2010b).

94 Arjunolic acid (AA: 2.3,23-trihydroxyolean-12-oic acid), found in nature as chiral triterpenoid saponin which is isolated from the bark of T. arjuna. This compound possess variety of biological activities like, antiasthmatic (Kalola \& Rajani 2006), antitumor (Wille et al. 2001), wound healing (Chaudhari \& Mengi 2006), antifungal (Masoko et al. 2008), antibacterial (Djoukeng et al. 2005), and inhibition of insects growth (Bhakuni et al. 2002). Despite variety of biological activities, AA is well-known for its cardioprotective role and proved to be beneficial against platelet aggregation and in lowering of blood pressure, lipid level, myocardial necrosis and coagulation and heart rate (Ghosh \& Sil 2013). Its beneficial effects might be due to the potent antioxidant activity, which is demonstrated by its free radical scavenging activity. This compound has shown to be effective in eliminating radicals produced due to nitric oxide, superoxide and hydroxyl at the cellular level (Ghosh \& Sil 2013; Manna et al. 2007). Moreover, it possess protective effects towards cells and tissues against toxicity induced by drugs or heavy metals (Ghosh et al. 2010a; Manna et al. 2007). Various biological activities have shown its prominent use in different diseases model but its safety profile on acute toxicity of AA in female SD rats to elucidate its therapeutic dose and safety in animals. The graphical representation of the study design is represented in Figure 1. 
116

117

118

119

120

121

122

123

124

125

2.1. Organic solvents for extraction and chromatographic separation were obtained from Active Fine Chemicals, Bangladesh. Melting points were determined on a digital melting point Apparatus of Cole-Parmer Ltd, UK (model SMP10). Thin Layer Chromatography (TLC) was run on Merck pre-coated TLC plates with $\mathrm{Si}_{60} \mathrm{~F}_{254}$. Plates were visualized by spraying with Lieberman-Burchard reagent followed by heating. Vacuum Liquid chromatography (VLC) was done using Silica gel $60(0.040-0.005 \mathrm{~mm})$, Merck, Germany. Open column chromatography was performed using Silica gel 60 (0.063-0.020 mm), Merck, Germany. Spectral data were obtained as follows: Infrared (IR) spectrum with a Shimadzu IR Prestige-2 FT-IR spectrophotometer, ultraviolet spectrum with a Shimadzu UV spectrophotometer (UV1800), Nuclear Magnetic Resonance (NMR) spectra with an ultra-shield Bruker Avance 400 $\mathrm{MHZ}$ in $\mathrm{CD}_{3} \mathrm{OD}$. The NMR spectra were recorded running gradients and using residual solvent peak (at 3.33 in ${ }^{1} \mathrm{H}-\mathrm{NMR}$ and middle peak of septate at 49.0 in ${ }^{13} \mathrm{C}-\mathrm{NMR}$ ) as internal reference.

\subsection{Plant collection}

Dried barks of Terminalia arjuna were collected from Bogura, a northern district of Bangladesh (Latitude: $24^{\circ} 51^{\prime} 3.53^{\prime \prime} \mathrm{N}$ and Longitude: $89^{\circ} 22^{\prime} 15.89^{\prime \prime} \mathrm{E}$ ) by Green Herbal Supply, Shapla Chattar, Motejheel, Dhaka 1000, Bangladesh. The plant materials were authenticated by a botanist of the Department of Pharmacy at East West University, Bangladesh. A voucher specimen of the dried bark of plant is on deposit at the East West University herbarium (voucher \# EWUH-PHRM-180001).

\subsection{Isolation of Arjunolic acid}

Dried barks of Terminalia arjuna were pulverized with a commercial grinding mill, and the coarse powder were kept in air-tight containers. A pilot scale extraction and an isolation unit were set up at Department of Pharmacy, East West University. Few batches of 
coarse powder of the bark $(3.0 \mathrm{~kg})$ were exhaustively extracted with EtOAc by Soxhlet apparatus using 10 thimbles. Each thimble contained $300 \mathrm{~g}$ of powder and was run 45 cycles (one cycle required 15 minutes). The extracting solvent was filtered, and the filtrate was

143 concentrated under reduced pressure by a rotary evaporator $\left(48^{\circ} \mathrm{C}\right)$ to obtain crude EtOAc 144 extract (53.5 g, yield: $2.7 \% \mathrm{w} / \mathrm{w}$ from dried sample). This crude extract was chromatographed 145 on silica gel by an open column $(4.0 \times 100 \mathrm{~cm})$ with step-gradient of petroleum ether (b.p. 60$146 \quad 80^{\circ} \mathrm{C}$ ) and EtOAc solvent system which yielded 86 fractions. Based on the analytical TLC 147 (solvent system: EtOAc-MeOH-AcOH 9.0:1.0:0.1) of the fractions, these sub-fractions were 148 then pooled into 16 fractions. The fr.13 (3.9 g), rich in triterpenoids, were further 149 chromatographed on silica open column $(4.0 \times 60 \mathrm{~cm})$ with step-gradient of $\mathrm{CHCl}_{3}-\mathrm{MeOH}$ to 150 get 11 fractions. Further crystallization of fr.7 to fr.9 with EtOAc yielded arjunolic acid as 151 shown in Figure 2.

\subsection{Experimental animals}

Acute oral toxicity test was conducted following the Organization for Economic Cooperation and Development (OECD) guideline, i.e., OECD Guideline 423 for the acute oral toxicity (OECD 2001). Eighteen female SD rats of 8-10 weeks with an average weight of $270 \pm 15 \mathrm{~g}$ were obtained from the Animal Experimental Unit, Faculty of Medicine, University of Malaya, Kuala Lumpur, Malaysia. All the animals were acclimatized for 7 days with 6 rats in a group were sheltered in 3 different groups before starting acute toxicity experiments. The temperature of animal house was maintained at $24{ }^{\circ} \mathrm{C}$, with a $12 \mathrm{~h} \mathrm{light} /$ dark cycle. All experimental procedure of animal handling was approved by the Institutional Animal Care and Use Committee (IACUC) with Ethics No. 2018-210605/TAY/R/AA 
163

164

165

166

167

168

169

170

171

172

173

174

175

176

177

178

179

180

181

182

183

(2018294), Faculty of Medicine, University of Malaya. Body weight of all the animals was recorded on individual basis before administration of the test compound (AA). The volume of the test dose was calculated based on the body weight of the individual rat. All rats used were nulliparous \& non-gravid, they were fed with standard pellet diet and water ad libitum.

\subsection{Acute oral toxicity test}

Arjunolic acid (AA) was administered by oral gavage to overnight fasted female rats by suspending it in $0.5 \%$ carboxymethyl cellulose $(\mathrm{CMC})$ in a total volume of $10 \mathrm{ml} / \mathrm{kg}$ body weight. The first test dose of $300 \mathrm{mg} / \mathrm{kg}$ body weight of AA was orally administered to the group 1. All the rats were carefully monitored for any changes in general behavioural, signs of toxicity and subsequent mortality after treatment with $1^{\text {st }}$ dose for 4 hours, followed by an observation period of 48 hours. Group 2 animals were administered with high dose of AA at $2000 \mathrm{mg} / \mathrm{kg}$ body weight, after 48 hours. At the same time, the $3^{\text {rd }}$ group (standard control) was treated with vehicle $(0.5 \% \mathrm{CMC})$ for comparative analysis based on the OECD guideline (OECD 2001). All rats were critically monitored throughout the study period and were carefully monitored for the first 30 minutes followed by 4 hours after AA and vehicle administration and finally once in 24 hours for two weeks. Animals were on observation for any changes in the fur, skin, mucous membranes, eyes and monitored for any behavioral changes on regular basis to maintain proper record. Moreover, special attention was given to check any signs of tremors, convulsions, salivation, lethargy, diarrhoea, coma, sleep and mortality.

Peer] reviewing PDF | (2019:07:39705:1:2:NEW 1 Oct 2019) 

prior to the administration of the test compound and then weekly for two weeks. The following equation was used to compute the percentage change in body weight.

$\%$ Body weight change $=\frac{\text { Bodyweight at the end of each week }- \text { initial body weight }}{\text { Initial body weight }} X 100$

189

190

191

192

193

194

195

196

197

198

199

200

201

202

203

204

205

206

207

\subsection{Hematology and serum biochemistry}

At the end of study period ( $15^{\text {th }}$ day), rats from all the 3 groups were euthanized by using appropriate dose of ketamine $(80 \mathrm{mg} / \mathrm{kg})$ and xylazine $(7 \mathrm{mg} / \mathrm{kg})$ following the established protocol by Animal Experimental Unit (AEU), University of Malaya. Blood (5ml) was collected by direct cardiac puncture and preserved in EDTA coated and plain vacutainers for hematological analysis; red blood cells (RBCs), white blood cells (WBCs), monocytes, neutrophils, lymphocytes, basophils and eosinophils. Moreover, for biochemical analysis, plain vacutainers were kept at room temperature for 15-20 min to let blood coagulate. Later blood samples were centrifuged at $5000 \mathrm{rpm}$ for $20 \mathrm{~min}$ at $4^{\circ} \mathrm{C}$ to obtain serum for renal function tests including calcium, uric acid, sodium, potassium, chloride, urea, creatinine, inorganic phosphate, and lipid profiles; HDL, LDL cholesterol, total cholesterol and triglycerides, as well as hepatic function test mainly total protein, albumin, globulin, total bilirubin, aspartate aminotransferase (AST), alanine aminotransferase (ALT).

\subsection{Histopathological observation}

Veterinarian from AEU, University of Malaya performed necropsies on all the animals complying established protocol. Subsequently, vital organs; heart, liver, lungs, 
208 kidneys, brain along with spleen, uterus, adrenal glands, stomach, ovaries, cervices, vagina, 209 urinary bladder and eyes were harvested by making fine incision on the midline. Blood was 210 wiped from the harvested tissues through the blotting paper and calibrated weighing balance 211 was used to measure relative organ weight (ROW). The ROW was computed with respect to 212 body weight at the time of sacrifice with the help of the following equation:

$$
R O W=\frac{\text { absolute weight of organ }}{\text { body weight at the time of sacrifice }} X 100
$$

Later, heart, liver, lungs, kidney, brain, spleen and pancreas were carefully fixed in $10 \%$ buffered solution of formalin and further processed by dehydrating in graded alcohol and xylene. The processed tissues were embedded in paraffin wax for histopathological examination. Importantly, for Oil O Red staining, sections of frozen tissues were used. After embedding process, sections of paraffin were cut into fine sections of $5 \mu \mathrm{m}$, shifted on glass slides and stained with hematoxylin and eosin $(\mathrm{H} \& \mathrm{E})$. In order to investigate fibrotic lesions in tissues, sections were stained with Massion trichrome (Abcam 150686), while Schiff (Abcam 150680) and Oil O red (Abcam 150681) respectively as per the manufacturer 226 protocol. Tissue sections were further observed under the fluorescence compound microscope (Eclipse Ni-U, Nikon corporation, Japan) for any kind of microscopic variations in the harvested tissues.

\subsection{Statistical analysis}

Results were expressed as the mean \pm standard deviation (SD). Normality of data was analyzed by Kolmogorov-Smirnov and Shapiro wilk test. The statistical variations between groups were analyzed by one-way analysis of variance (ANOVA) using SPSS 
231

232

233

234

235

236

237

238

239

240

241

242

243

244

245

246

247

248

249

250

251

252

253

254

255

package version 22 (IBM, SPSS Statistics, Inc., Chicago, IL, USA). Differences were considered significant at $(p<0.05)$.

\section{Results}

\subsection{Arjunolic acid:}

Crystallization of fr. 7 to fr. 9 with EtOAc yielded AA 1.20g as shown in Figure 2. The obtained crystals were white amorphous powder; m.p: $>300^{\circ} \mathrm{C}$ (decom.); UV $\lambda_{(\mathrm{MeOH})} \mathrm{nm}$ : 204 (end absorption); IR $v_{(\mathrm{KBr})} \mathrm{cm}^{-1}: 1047.4,1197.9,1386.9,1461.1,1637.6,1694.5,2645.5$, 2884.7, 2942.5, 3416.1; ${ }^{1} \mathrm{H}-\mathrm{NMR}\left(\mathrm{CD}_{3} \mathrm{OD}\right):: 0.72\left(3 \mathrm{H}, \mathrm{s}, \mathrm{H}_{3}-24\right), 0.83\left(3 \mathrm{H}, \mathrm{s}, \mathrm{H}_{3}-25\right), 0.87-$ $0.92(1 \mathrm{H}, \mathrm{m}), 0.96\left(3 \mathrm{H}, \mathrm{s}, \mathrm{H}_{3}-26\right) 0.97$ (3H,s, H $\left.3-30\right), 1.02\left(3 \mathrm{H}, \mathrm{s}, \mathrm{H}_{3}-29\right), 1.03\left(3 \mathrm{H}, \mathrm{s}, \mathrm{H}_{3}-27\right)$, 1.31-1.35 (4H, m), 1.45-1.59 (3H, m), 1.67-1.81 (6H, m), 1.91-1.22 (1H, m), $2.00(1 \mathrm{H}, \mathrm{d}$, $J=8.8 \mathrm{~Hz}), 2.33(1 \mathrm{H}, \mathrm{dd}, J=4,4 \mathrm{~Hz}) 3.28-3.43(7 \mathrm{H}, \mathrm{m}) 2.92(1 \mathrm{H}, \mathrm{d}, \mathrm{J}=9.6) 3.08(1 \mathrm{H}, \mathrm{br} \mathrm{s}) 3.61$ $\left(1 \mathrm{H}, \mathrm{m}, \mathrm{H}_{\mathrm{b}}-11\right) 3.69(1 \mathrm{H}, \mathrm{dd}, J=4.0,8 \mathrm{~Hz}, \mathrm{H}-2), 3.84(1 \mathrm{H}, \mathrm{d}, J=8 \mathrm{~Hz}, \mathrm{H}-3), 5.40(1 \mathrm{H}, \mathrm{d}, J=4$ $\mathrm{Hz}, \mathrm{H}-12) ;{ }^{13} \mathrm{C}-\mathrm{NMR}\left(\mathrm{CD}_{3} \mathrm{OD}\right): 48.05$ (C-1), 69.51 (C-2) 78.33 (C-3), 43.07 (C-4), 49.06 (C5) 19.70 (C-6), 33.28 (C-7), 40.50 (C-8), 49.21 (C-9) 39.38 (C-10), 24.90 (C-11), 124.81 (C12), 144.43 (C-13), 42.67 (C-14), 29.43 (C-15), 28.44 (C-16), 47.12 (C-17), 45.06 (C-18), 48.02 (C-19), 31.52 (C-20), 33.81 (C-21), 29.51 (C-22), 62.40 (C-23), 17.01 (C-24), 17.60 (C-25), 17.37 (C-26), 25.17 (C-27), 178.58 (C-28). 26.35 (C-29), 24.98 (C-30).

\subsection{Analysis of general sign and behavior}

Oral administration of AA at $300 \mathrm{mg} / \mathrm{kg}$ and $2000 \mathrm{mg} / \mathrm{kg}$ body weight showed no signs of mortality. During the whole study period no signs of toxicity was observed. No alterations in eyes, skin, fur, mucous membrane and behavioral patterns were noted. Moreover, there were no signs of diarrhoea, salivation, coma, sleep, lethargy, and tremors 
as shown in Table 1. Based on the general observation from the study, AA did not show any lethal effect on animals at tested dose levels.

258

\subsection{Effect of AA on body weight, relative organ weight, food and water consumption}

The average body weight of normal animals was observed as $263.33 \pm 12.11 \mathrm{gm}$, which shows non-significant difference when compared to control group $(p>0.05)$, as stated in (Table 2). Furthermore, all the harvested organs were recorded normal weight and regular morphology without any macroscopic lesions as shown in Figure 3 and 4, while ROW between treated and control groups exhibited non-significant variations ( $p>$ 0.05) presented in Table 3.

Daily food and water intake of the treatment groups revealed non-significant difference $(p>0.05)$ when compared with the normal animals (Table 4).

270

271

\subsection{Effect of AA on hematological and biochemical profile}

272

The hematological parameters are summarized in Table 5. Treatment groups showed non-significant changes $(p>0.05)$ in the hematological parameters; RBCs, hemoglobin, WBCs, packed cell volume (PCV), mean corpuscular volume (MCV), mean corpuscular hemoglobin $(\mathrm{MCH})$ and mean corpuscular hemoglobin concentration $(\mathrm{MCHC})$, when compared with the normal control. 
amino transferase (ALT/SGPT), aspartate amino transferase (AST/SGOT), alkaline

280

281

282

283

284

285

286

287

288

289

290

291

292

293

294

295

296

297

298

299

300

301

phosphatase (AP), total proteins, albumin and globulin levels of the treatment groups were not affected and observed to be normal when compared with the control group $(p>0.05)$, shown in Table 6.

\subsection{Histopathological findings}

Histopathological examination was carried out to investigate any structural alterations in the harvested tissues. Four different staining; hematoxylin and eosin (H\&E) [Figure 5 and 6], Masson trichrome (MT) [Figure 7 and 8], Periodic acid Schiff (PAS) [Figure 9 and 10] and Oil O Red (Figure 11 and 12) were used for the microscopic investigation of the harvested tissues; heart, liver, kidneys, lungs, brain, spleen and pancreas. The microscopical findings, did not express any gross pathological and microscopical changes in the treatment groups, when compared to the control animals. Moreover, during gross examination all the organs retained their normal textures without any abnormal changes in the color and appearance. Importantly, no structural alterations were detected in different tissues using specific resolution under the microscope.

\section{Discussion}

Since time immemorial plant-derived botanicals have important role in the management of various diseases. Natural products and phytochemicals have potential to develop as therapeutics or might have essential role to be used as a precursors for the synthesis of potent drug candidates. (Ifeoma \& Oluwakanyinsola 2013). However, at the 
same time investigation of potential toxicity of plant derived compounds is crucial prior to their usage in various disease models.

304

In the present study, arjunolic acid (AA) is isolated from the bark of Terminalia arjuna,

which have a $\mathrm{R}_{\mathrm{f}}$ value of 0.62 with EtOAc-MeOH-AcOH 9.0:1.0:0.1 solvents system on silica gel TLC, and gave characteristic purple color of pentacyclic triterpenoid by spraying with Lieberman-Burchard reagent. It has shown broad absorption band from $2500 \mathrm{~cm}^{-1}$ in IR spectra which revealed, the compound is a triterpenoid acid. Strong sharp absorption band of carbonyl carbon at $1637 \mathrm{~cm}^{-1}$ also supported the fact. ${ }^{1} \mathrm{H}-\mathrm{NMR}$ spectrum of the compound showed an olefinic resonance peak at $\delta 5.40(\mathrm{~d}, J=4 \mathrm{~Hz})$ indicating presence of a double bond. Beside that, it showed six methyl signals at $\delta 0.72(3 \mathrm{H}, \mathrm{s}), \delta 0.83(3 \mathrm{H}, \mathrm{s}), \delta$ $0.96(3 \mathrm{H}, \mathrm{s}), \delta 0.97(3 \mathrm{H}, \mathrm{s}), \delta 1.02(3 \mathrm{H}, \mathrm{s})$ and $\delta 1.03(3 \mathrm{H}, \mathrm{s}) .{ }^{13} \mathrm{C}-\mathrm{NMR}$ and DEPT $\left(135^{\circ}\right)$. Spectral analysis revealed the presence of six primary $\operatorname{sp}^{3}$ carbons at $\delta 17.01, \delta 17.37, \delta$ $17.60, \delta 24.98, \delta 25.17, \delta 26.35$, ten secondary $\mathrm{sp}^{3}$ carbons at $\delta 19.70, \delta 24.90, \delta 28.44, \delta$ $29.43, \delta 29.51, \delta 33.28, \delta 33.81, \delta 48.02, \delta 48.05, \delta 62.4$, five tertiary $\mathrm{sp}^{3}$ carbons at $\delta$ $45.06, \delta 49.06, \delta 49.21, \delta 69.51, \delta 78.33$, and six quaternary $\mathrm{sp}^{3}$ carbons at $\delta 31.52, \delta$ $39.38, \delta 40.5, \delta 42.67, \delta 43.07$ and $\delta 47.12$. Moreover, ${ }^{13} \mathrm{C}-\mathrm{NMR}$ spectrum also shown a tertiary $\mathrm{sp}^{2}$ carbon at $\delta 124.81$, and two quaternary $\mathrm{sp}^{2}$ carbon at $\delta 144.43$ and $\delta 178.58$. Based on the spectroscopic analysis, the isolated compound was identified as arjunolic acid. Importantly, our findings are in consistent with the data published in the literature (King et al. 1954; Mann et al. 2012; Ramesh et al. 2012).

This study aimed to identify toxicological profile of AA which have shown to possess pleiotropic biological activities on various in vitro and in vivo study models like antibacterial, anti-tumor, antioxidant, antiasthmatic, anti-fungal and cardioprotective effects. 
However, AA has multiple pharmacological activities, the scientific data on its toxicological and safety profile in animals remains to be elucidated. establish safe dosage for further preclinical study on subacute disease model. In this study, the selection of rat model is based on the resemblance of physiology with humans and the convenience route of administration and to integrate further pharmacokinetic parameters.

In acute toxicity study, rats were divided into 3 groups, one served as control (vehicle) while other two (treatment groups) received orally AA at a dose of $300 \mathrm{mg} / \mathrm{kg}$ and $2000 \mathrm{mg} / \mathrm{kg}$ based on (OECD 2001). Prior to AA administration, all the animals underwent fasting for approximately 12 hours to avoid its interaction with food and other enzymes of digestive tract (Kumar \& Lalitha 2013).

No mortality was noted at the first test dose of $300 \mathrm{mg} / \mathrm{kg}$ in the treatment group which led to the administration of next high dose of $2000 \mathrm{mg} / \mathrm{kg}$ body weight.

All the groups were monitored carefully for two weeks for any signs of associated toxicity and mortality. All rats in the treatment groups displayed no evident symptoms of towards identification of symptoms associated with toxicity (Jothy et al. 2011). No major alterations in the physical characteristics of fur, skin, eyes, salivation, mucous membrane, sleep and behavioral pattern were observed. Moreover, there were no signs of diarrhoea, coma, tremors and lethargy (Table 1). In addition, both the treatment groups exhibited normal increase in the body weight, compared to the control group without any significant 
348

349

350

351

352

353

354

355

356

357

358

359

360

361

362

363

364

365

366

367

368

369

370 variation. Interestingly, our results showed non-significant changes in the relative organ weight (ROW), as shown in Table 2 and 3. The steady increase in the body weight and normal organ weight assumes AA has no devastating role in the normal growth and development process of the animals. Importantly, the organ weight is of prime importance and considered as a bench mark to body weight ratio, reflecting treatment related toxicity (Sohail et al. 2018).

Estimation of therapeutic window is also an important parameter that provides benefit to risk assessment of the drug/compound, animal model is one of the approach to unveil this aspect (Al-Afifi et al. 2018). Normal food and water intake throw light on the normal metabolic processes, as observed in the treated animals (Table 4). The results are in agreement with Yuet et al, who showed methanolic extract of Euphorbia hirta did not express any variations in the food \& water intake and body weights of rats (Yuet Ping et al. 2013). Moreover, it is essential to evaluate food and water intake of the test compound after single oral dose to substantiate the safety, as appropriate consumptions of nutrients are valued to the health status of animals and highlight proper response to the treatment (Sathish et al. 2012). The results of body weight and dietary consumption shows that AA is safe even at high dose.

Result of hematological analysis revealed that AA might have normal role in the production and development process of blood cells, as the data shows non-significant alterations in the treatment vs control group (Table 5). Hematological parameters point out minor and major alterations in the functioning of different organs (Al-Afifi et al. 2018). Moreover, our finding is supported by the previous researchers (Petterino \& ArgentinoStorino 2006; Said \& Abiola 2014). The hematological parameters provide clear 
371

372

373

374

375

376

377

378

379

380

381

382

383

384

385

386

387

388

389

390

391

392

393

understanding of any signs of toxicity, as hematological system is very sensitive against the effects of any toxin entering living system and have higher diagnostic value for signs of intoxication (Olson et al. 2000). The foremost medium for transportation of nutrients and drugs in the living system is blood, whereas blood cells and proteins are primarily exposed to the considerable concentration of toxic compounds. Therefore, any damage to the blood components will adversely affect the smooth functioning of organs in animals and humans (Abotsi et al. 2011).

Investigation of renal and hepatic functions are considered as crucial and reliable test in the toxicity study. As we know plant extracts contains various phytochemicals, it is possible that one or few among them react with liver and kidney enzymes or possibly due to the synergism (Olorunnisola et al. 2012). In toxicity studies, the level of creatinine in the serum represents the clear picture to predict renal physiology. It remains to be in normal ranges, as daily synthesis and renal excretion are in equilibrium in healthy mammals (Yilmaz et al. 2007). In our findings, renal function tests, creatinine and urea were noted in the normal ranges which is in agreement with the previous published articles (P'ng et al. 2013).

Similarly, the liver enzymes, ALT, AST and AP levels were observed in the normal range after treatment with AA. These are the prominent enzymes produced by liver cells, their deregulations may lead to increase their level in the serum, thus, serve as an essential indices to elucidate inflammation, necrosis and provide clear understanding of intoxication in the liver tissues (Imafidon \& Okunrobo 2012) (Yakubu et al. 2003). Moreover, AA did not alter serum albumin and globulin concentration and hepatocellular functions which depicts its safety on the liver tissue (Table 6). In animals, normal functionality of liver and 
kidney is important, which is in consistent with Loha et al findings, that reveals no alteration to hematological and biochemical parameters in rats upon administration of Syzygium guineense (Loha et al. 2019). The outcomes on hematological and biochemical profiles suggest that AA did not cause toxicity at organ level, which act as a basic functions test and assure serum biochemical as a crucial parameters in the toxicity study of phytochemicals (Bariweni et al. 2018).

Furthermore, it is important to consider histopathological study with multiple staining techniques; H\&E, MT, PAS and Oil O Red on vital organs and visualize them with appropriate microscope for in depth and critical analysis at cellular levels. In this study, the photomicrographs of heart and liver from both the treatment and control animals exhibited regular morphology and normal architecture. The heart tissues showed normal cardiac muscle fibres with centrally placed nucleus and transverse striations along with properly localized intercalated discs. Perinuclear halo, clear space around the nucleus were visible, with no signs of necrotic injury, hypertrophy, fibrosis and accumulation of fats with normal glycogen content were observed under microscope. Moreover, liver tissues displayed regular pattern in hepatocytes and polygonal shape with radiating cords, and visible congestion of hepatic sinusoids. There were no lesions related with necrosis or apoptosis, no hemorrhages and fatty changes were seen around the central vein, sinusoids and portal triad. Importantly, no signs of infiltration of monocytes and macrophages were detected in the liver. Brain tissues presented the normal architecture in the different regions without any signs of morphological changes, as necrosis and distorted neurons in all the treatment and control group. The pyramidal neurons of cerebral cortex exhibited regular shape with scant and delicate cytoplasm. Glial cells were visible with a uniform outline in all the 
417

418

419

420

421

422

423

424

425

426

427

428

429

430

431

432

433

434

435

436

437

438

439

groups. Thorough microscopic analysis of lungs revealed normal honeycomb appearance

of alveoli lined by flattened squamous cells, whereas, bronchioles were surrounded with epithelium and smooth muscles with no signs of congestion, necrosis and apoptotic cell death in the treatment groups.

On the other hand, kidney tissues reflected no morphological alterations in glomerular structure as well as in proximal and distal tubules. Nephrons appeared to be normal without any damage to the blood vessels and no signs of necrosis were observed in the tubules. Moreover, renal tissues displayed no accumulation of collagen, fats and glycogen in the treatment groups. In pancreas, acinar cells were normal with either round or oval shape, islets of Langerhans were visible and appeared in the form of small groups with lightly stained cytoplasm. While spleen, showed normal morphology with white and red pulp. White pulp appeared to be regular with diffused and dense distribution of lymphocytes and red pulp showed sinusoids without any signature of apoptotic and necrotic lesions. These histopathological investigations are in line with Loha and Yuet et al, who reported no morphological differences in tissues of control and treatment groups (Loha et al. 2019; Yuet Ping et al. 2013).

As we know histopathological examination of vital organs and tissues serves as a basic test to judge the safety of any drug candidate (Greaves 2011). H\&E staining is most widely used to illustrates the architecture of cytoplasm and nucleus, emphasizing more towards the morphological aspects of tissues to observe any gross pathological changes (Fischer et al. 2008), whereas, masson trichrome describes the alterations in connective and soft tissue components in terms of sclerotic lesions, perivascular fibrosis and scar formation, which indicates direct damage to the vital organs due to chemical and 
440

441

442

443

444

445

446

447

448

449

450

451

452

453

454

455

456

457

458

459

460

461

462

mechanical injury (Cabibi et al. 2015). Likewise, PAS staining is another special stain to demonstrate the presence of neutral mucopolysaccharides, particularly glycogen as well as it pinpoints thickening of basement membrane in tissue structures to delineate derangements in the organization of tissues. Furthermore, Oil O Red staining reveals abnormal fat deposition in the tissues and widely employed in experimental studies to expose any metabolic abnormality due to intoxication, as the abnormal deposition of neutral fats indicates metabolic malfunctioning of the organs upon injury (Kumar et al. 2010).

Therefore, from histopathological analysis, we conclude that AA did not produce any abnormal changes and structural alterations at high dose in female SD rats. The overall outcomes of this study permit to rank AA under category 5 with low acute toxicity exposure, according to the Globally Harmonized System of Classification and Labelling of Chemicals (OECD guidelines 423) (OECD 2001). These results are in agreement with the study conducted by $\mathrm{Ng}$ 'uni et al, who showed that Galenia africana extract can be categorized under cetagory 5 , when administered orally in the single dose of $2000 \mathrm{mg} / \mathrm{kg}$ in female Sprague Dawley rats and is in compliance with Globally Harmonized System of Classification and Labelling of Chemicals (Ng'uni et al. 2018). Previous findings support this study by establishing AA as a safe candidate up to $2000 \mathrm{mg} / \mathrm{kg}$ after single dose administration.

However, in vitro testing on cell lines and other alternative methodologies are the limitations of this study, as careful and in-depth data validation is required to meet high standards of safety evaluation. It is difficult to establish a safe starting animal dose through in-vitro testing. Thus, it appears crucial and of prime importance to perform in vivo toxicity 
463

464

465

466

467

468

469

470

471

472

473

474

475

476

477

478

479

480

481

482

483

484

485

486

487

488 testing in order to accomplish safety profile of the drug candidates prior to the drug development. Importantly, $\mathrm{LD}_{50}$ obtained from animals can only provide an effective dose concentration for humans in preclinical phase, as it is practically impossible to perform acute toxicity on humans from ethical point of view. In the context of future study, we intend to perform further study on the disease model and for that we need to have complete toxicological data from rodent model with the possible therapeutic dose.

\section{Conclusions}

Our current toxicological investigation suggest that AA is non-toxic even at high dose, it neither exhibited any alterations to the hematological and biochemical parameters nor showed any signs of physical or behavioral anomalies. Moreover, no mortality or major histopathological changes was observed in treated rats when compared with control groups, thus, establishing AA as a safe medicinal agent in appropriate dosages. However, warrant in-depth study on subacute/chronic disease model to determine its potential therapeutic role on targeted ailments.

\section{Acknowledgements}

The current project is sponsored by "Ageing and Quality of Life", Flagship Research Grant (TUFR/2017/002/01) supported by Taylors University, Malaysia. 
489

490

491

492

493

494

495

496

497

498

499

500

501

502

503

504

505

506

507

508

509

510

\section{References}

Abotsi WK, Ainooson GK, Gyasi EB, and Abotsi WKM. 2011. Acute and sub-acute toxicity studies of the ethanolic extract of the aerial parts of Hilleria latifolia (Lam.) H. Walt.(Phytolaccaceae) in rodents. West African Journal of Pharmacy 22:27-35..

Al-Afifi NA, Alabsi AM, Bakri MM, and Ramanathan A. 2018. Acute and sub-acute oral toxicity of Dracaena cinnabari resin methanol extract in rats. BMC complementary and alternative medicine 18:1-14.

Amos TN, Bashir L, Saba SE, Saba MA, Mohammed BM, Abdulsalam IH, and Josiah GJ. 2015. Phytochemicals and acute toxicity profile of aqueous and methanolic extracts of Crateva adansonii leaves in Swiss albino rats. Asian Journal of Biochemistry 10(4):173-179.

Bariweni MW, Yibala OI, and Ozolua RI. 2018. Toxicological studies on the aqueous leaf extract of Pavetta crassipes (K. Schum) in rodents. Journal of Pharmacy \& Pharmacognosy Research 6:1-16.

Bhakuni R, Shukla Y, Tripathi A, Prajapati V, and Kumar S. 2002. Insect growth inhibitor activity of arjunolic acid isolated from Cornus capitata. Phytotherapy Research 16(S1):68-70.

Cabibi D, Bronte F, Porcasi R, Ingrao S, Giannone AG, Maida M, Grazia Bavetta M, Petta S, Di Marco V, and Calvaruso V. 2015. Comparison of histochemical stainings in evaluation of liver fibrosis and correlation with transient elastography in chronic hepatitis. Analytical Cellular Pathology 2015:1-7.

Chaudhari M, and Mengi S. 2006. Evaluation of phytoconstituents of Terminalia arjuna for wound healing activity in rats. Phytotherapy Research 20(9):799-805. 
511 Djoukeng J, Abou-Mansour E, Tabacchi R, Tapondjou A, Bouda H, and Lontsi D. 2005. 512 Antibacterial triterpenes from Syzygium guineense (Myrtaceae). Journal of 513 Ethnopharmacology 101(1-3):283-286.

514 Facundo VA, Rios KA, Medeiros CM, Militão JS, Miranda ALP, Epifanio RdA, Carvalho MP, 515 Andrade AT, Pinto AC, and Rezende CM. 2005. Arjunolic acid in the ethanolic extract of 516 Combretum leprosum root and its use as a potential multi-functional phytomedicine and 517 drug for neurodegenerative disorders: anti-inflammatory and anticholinesterasic activities. Journal of the Brazilian Chemical Society 16(6B):1309-1312.

519 Farsi E, Shafaei A, Hor SY, Ahamed MBK, Yam MF, Asmawi MZ, and Ismail Z. 2013. 520 Genotoxicity and acute and subchronic toxicity studies of a standardized methanolic extract 521 of Ficus deltoidea leaves. Clinics 68(6):865-875.

522

Fischer AH, Jacobson KA, Rose J, and Zeller R. 2008. Hematoxylin and eosin staining of tissue 523 and cell sections. Cold Spring Harbor Protocols 3(5):1-3.

524

525

526

527

528 529

530

531

532

Ghosh J, Das J, Manna P, and Sil PC. 2010a. Arjunolic acid, a triterpenoid saponin, prevents acetaminophen (APAP)-induced liver and hepatocyte injury via the inhibition of APAP bioactivation and JNK-mediated mitochondrial protection. Free Radical Biology and Medicine 48(4):535-553.

Ghosh J, Das J, Manna P, and Sil PC. 2010b. Protective effect of the fruits of Terminalia arjuna against cadmium-induced oxidant stress and hepatic cell injury via MAPK activation and mitochondria dependent pathway. Food Chemistry 123(4):1062-1075.

Ghosh J, and Sil PC. 2013. Arjunolic acid: a new multifunctional therapeutic promise of alternative medicine. Biochimie 95(6):1098-1109. 
533 Greaves P. 2011. Histopathology of preclinical toxicity studies: interpretation and relevance in 534 drug safety evaluation: Academic Press.

535 Ifeoma O, and Oluwakanyinsola S. 2013. Screening of herbal medicines for potential toxicities. $536 \quad$ New Insights into Toxicity and Drug Testing: IntechOpen.

537 Imafidon K, and Okunrobo L. 2012. Study on biochemical indices of liver function tests of albino

538

539

540

541

542

543

544

545

546

547

548

549

550

551

552

553

554

555 rats supplemented with three sources of vegetable oils. Nigerian Journal of Basic and Applied Sciences 20(2):105-110.

Jothy S, Zakaria Z, Chen Y, Lau YL, Latha LY, and Sasidharan S. 2011. Acute oral toxicity of methanolic seed extract of Cassia fistula in mice. Molecules 16:5268-5282.

Kalola J, and Rajani M. 2006. Extraction and TLC Desitometric determination of triterpenoid acids (Arjungenin, Arjunolic Acid) from Terminalia arjuna stem bark without interference of tannins. Chromatographia 63(9-10):475-481.

King F, King T, and Ross J. 1954. The chemistry of extractives from hardwoods. Part XVIII. The constitution of arjunolic acid, a triterpene from Terminalia arjuna. Journal of the Chemical Society (Resumed):3995-4003.

Kumar GL, Kiernan JA, and Dako A. 2010. Education Guide-Special Stains and $H \&$ E: Pathology: Dako North America.

Kumar VK, and Lalitha K. 2013. Acute oral toxicity studies of Anacyclus pyrethrum DC root in albino rats. International Journal of Pharmacy and Pharmceutical Sciences 5:675-678.

Loha M, Mulu A, Abay SM, Ergete W, and Geleta B. 2019. Acute and Subacute Toxicity of Methanol Extract of Syzygium guineense Leaves on the Histology of the Liver and Kidney and Biochemical Compositions of Blood in Rats. Evidence-Based Complementary and Alternative Medicine 2019:1-15. 
556 Mann A, Ibrahim K, Oyewale AO, Amupitan JO, Fatope MO, and Okogun JI. 2012. Isolation and 557 elucidation of three triterpenoids and its antimycobacterial activity of Terminalia 558 avicennioides. American Journal of Organic Chemistry 2(2):14-20.

559 Manna P, Sinha M, Pal P, and Sil PC. 2007. Arjunolic acid, a triterpenoid saponin, ameliorates 560 arsenic-induced cyto-toxicity in hepatocytes. Chemico-biological interactions 170(3):187-

561 200.

562

Masoko P, Mdee L, Mampuru L, and Eloff J. 2008. Biological activity of two related triterpenes

563

564 isolated from Combretum nelsonii (Combretaceae) leaves. Natural product research 22(12):1074-1084.

565 566

Ng'uni T, Klaasen JA, and Fielding BC. 2018. Acute toxicity studies of the South African 567 medicinal plant Galenia africana. Toxicology reports 5:813-818.

567 568

569

OECD. 2001. OECD Guidelines for testing of chemicals. Acute oral toxicity-acute toxic class method, guideline no 423. Organisation for Economic Cooperation and Development, Rome 2001.

570

571

Olorunnisola O, Bradley G, and Afolayan A. 2012. Acute and sub-chronic toxicity studies of 572 methanolic extract of Tulbaghia violacea rhizomes in Wistar rats. African Journal of Biotechnology 11(83): 14934-14940.

573

Olson H, Betton G, Robinson D, Thomas K, Monro A, Kolaja G, Lilly P, Sanders J, Sipes G, and 574 Bracken W. 2000. Concordance of the toxicity of pharmaceuticals in humans and in

575 animals. Regulatory Toxicology and Pharmacology 32(1):56-67.

576

577

578

P'ng XW, Akowuah GA, and Chin JH. 2013. Evaluation of the sub-acute oral toxic effect of methanol extract of Clinacanthus nutans leaves in rats. Journal of Acute Disease 2(1):2932. 
579 Pariyani R, Safinar Ismail I, Azam AA, Abas F, Shaari K, and Sulaiman MR. 2015. Phytochemical 580 screening and acute oral toxicity study of Java tea leaf extracts. BioMed research $581 \quad$ international 2015:1-8.

582 Petterino C, and Argentino-Storino A. 2006. Clinical chemistry and haematology historical data 583 in control Sprague-Dawley rats from pre-clinical toxicity studies. Experimental and 584 Toxicologic Pathology 57(3):213-219.

585 Ramesh AS, Christopher JG, Radhika R, Setty C, and Thankamani V. 2012. Isolation, 586 characterisation and cytotoxicity study of arjunolic acid from Terminalia arjuna. Natural $587 \quad$ product research 26(16):1549-1552.

588 Said NM, and Abiola O. 2014. Haematological profile shows that inbred Sprague Dawley rats 589 have exceptional promise for use in biomedical and pharmacological studies. Asian journal 590 of biomedical and pharmaceutical sciences 4(37):33-37.

591 Sathish R, Anbu J, Murgesan M, Ashwini A, and Kumar A. 2012. Toxicity study on siddha 592 formulation mega sanjeevi mathirai in albino rats. International Journal of Pharma and Bio Sciences 3:121-130.

594

595

596

597

598 599

600
Sohail MF, Hussain SZ, Saeed H, Javed I, Sarwar HS, Nadhman A, Rehman M, Jahan S, Hussain I, and Shahnaz G. 2018. Polymeric nanocapsules embedded with ultra-small silver nanoclusters for synergistic pharmacology and improved oral delivery of Docetaxel. Scientific reports $\mathbf{8}: 1-11$.

Thelingwani R, and Masimirembwa C. 2014. Evaluation of herbal medicines: value addition to traditional medicines through metabolism, pharmacokinetic and safety studies. Current drug metabolism 15(10):942-952. 
601 Wille PR, Ribeiro-do-Valle RM, Simões CM, Gabilan NH, and Nicolau M. 2001. Effect of 602 quercetin on tachykinin-induced plasma extravasation in rat urinary bladder. Phytotherapy

603 Research 15(5):444-446.

604

Yakubu M, Bilbis L, Lawal M, and Akanji M. 2003. Effect of repeated administration of sildenafil

605 citrate on selected enzyme activities of liver and kidney of male albino rats. Nigerean 606 Journal of Pure \& Applied Science 18:1395-1400.

607 Yang M, Wu Z, Wang Y, Kai G, Njateng GSS, Cai S, Cao J, and Cheng G. 2019. Acute and 608 subacute toxicity evaluation of ethanol extract from aerial parts of Epigynum auritum in 609 mice. Food and Chemical Toxicology 131(2019):1-8.

610 Yilmaz O, Yurt Lambrecht F, Soylu A, Durkan K, and Kavukcu S. 2007. Biodistribution of 99m 611 technetium-labeled creatinine in healthy rats. Brazilian Journal of Medical and Biological $612 \quad$ Research 40:807-812.

613 Yuet Ping K, Darah I, Chen Y, Sreeramanan S, and Sasidharan S. 2013. Acute and subchronic 614 toxicity study of Euphorbia hirta L. methanol extract in rats. BioMed Research

615 International 2013:1-14.

616 


\section{Table 1 (on next page)}

General observation and behavioral analysis

General observation and behavioral analysis 
3 Table 1. General observation and behavioral analysis

\begin{tabular}{|c|c|c|c|c|c|c|}
\hline \multirow[t]{2}{*}{ Observation } & \multicolumn{2}{|c|}{ Control } & \multicolumn{2}{|c|}{ AA $(300 \mathrm{mg} / \mathrm{kg})$} & \multicolumn{2}{|c|}{$\mathrm{AA}(2000 \mathrm{mg} / \mathrm{kg})$} \\
\hline & $4 h$ & $24 h$ & $4 h$ & $24 h$ & $4 h$ & $24 h$ \\
\hline Eyes & $\mathrm{NC}^{*}$ & $\mathrm{NC}$ & $\mathrm{NC}$ & $\mathrm{NC}$ & $\mathrm{NC}$ & $\mathrm{NC}$ \\
\hline Skin and fur & $\mathrm{NC}$ & $\mathrm{NC}$ & $\mathrm{NC}$ & $\mathrm{NC}$ & $\mathrm{NC}$ & $\mathrm{NC}$ \\
\hline Lethargy & NO & NO & NO & NO & NO & NO \\
\hline Sleep & Normal & Normal & Normal & Normal & Normal & Normal \\
\hline Diarrhea & $\mathrm{NO}^{*}$ & NO & NO & NO & NO & NO \\
\hline Coma & NO & NO & NO & NO & NO & NO \\
\hline Tremors & NO & NO & NO & NO & NO & NO \\
\hline Mucous membrane & $\mathrm{NC}$ & $\mathrm{NC}$ & $\mathrm{NC}$ & $\mathrm{NC}$ & $\mathrm{NC}$ & $\mathrm{NC}$ \\
\hline Behavioral patterns & Normal & Normal & Normal & Normal & Normal & Normal \\
\hline Salivation & Normal & Normal & Normal & Normal & Normal & Normal \\
\hline
\end{tabular}

4 *Not Observed

$5 *$ No Change 
Table 2 (on next page)

Percentage gain in body weight $(\mathrm{g})$ of rats at each week

Percentage gain in body weight $(\mathrm{g})$ of rats at each week 
1

2

3

4

5

6

8

9

10

11

12

13

14

15

16

17
Table 2. Percentage gain in body weight $(\mathrm{g})$ of rats at each week

\begin{tabular}{ccccc}
\hline Week & Control & AA $(\mathbf{3 0 0 m g} / \mathbf{k g})$ & AA $(\mathbf{2 0 0 0 m g} / \mathbf{k g})$ & $\boldsymbol{P}$-value \\
\hline Week 1 (\%) & $5.66 \pm 1.65$ & $5.90 \pm 2.78$ & $9.29 \pm 4.58$ & 0.13 \\
& & & & \\
Week 2 (\%) & $12.74 \pm 1.64$ & $11.10 \pm 2.73$ & $13.17 \pm 6.77$ & 0.688 \\
\hline
\end{tabular}

Weck $2 \%$ n.
Values expresse $\mathrm{d}$ as mean \pm standard deviatio n. 
Table 3(on next page)

Relative organ weight $(\mathrm{g})$ of rats at time of sacrifice

Relative organ weight $(\mathrm{g})$ of rats at time of sacrifice 
2 Table 3. Relative organ weight (g) of rats at time of sacrifice

3

4

5

6

7

8

9

10

11

12

13

14

AA $(300 \mathrm{mg} / \mathrm{kg})$

AA (2000mg/kg)

$P$-value

Brain

$0.632 \pm 0.035$

$0.750 \pm 0.121$

$0.694 \pm 0.083$

0.098

Heart

$0.267 \pm 0.001$

$0.269 \pm 0.002$

$0.268 \pm 0.003$

0.359

Stomach

$0.779 \pm 0.065$

$0.815 \pm 0.200$

$0.861 \pm 0.201$

0.704

Lungs

$0.433 \pm 0.002$

$0.432 \pm 0.003$

$0.433 \pm 0.002$

0.784

Liver

$2.947 \pm 0.093$

$3.176 \pm 0.363$

$3.104 \pm 0.217$

0.299

Pancreas

$0.447 \pm 0.003$

$0.446 \pm 0.003$

$0.445 \pm 0.004$

0.703

Spleen

$0.217 \pm 0.021$

$0.255 \pm 0.055$

$0.233 \pm 0.030$

0.271

Left Kidney

$0.262 \pm 0.001$

$0.260 \pm 0.002$

$0.262 \pm 0.001$

0.132

Right Kidney

$0.262 \pm 0.002$

$0.261 \pm 0.003$

$0.263 \pm 0.003$

0.489

Left Ad gland

$0.021 \pm 0.004$

$0.021 \pm 0.003$

$0.023 \pm 0.003$

0.579

Right Ad gland

$0.020 \pm 0.003$

$0.019 \pm 0.003$

$0.024 \pm 0.005$

0.144

Urinary bladder

$0.033 \pm 0.002$

$0.032 \pm 0.002$

$0.033 \pm 0.003$

0.880

Uterus

$0.427 \pm 0.051$

$0.526 \pm 0.178$

$0.471 \pm 0.057$

0.342

Cer/Vag

$0.066 \pm 0.002$

$0.065 \pm 0.002$

$0.067 \pm 0.003$

0.504

Left Ovary

$0.036 \pm 0.001$

$0.036 \pm 0.003$

$0.036 \pm 0.003$

0.936

Right Ovary

$0.037 \pm 0.001$

$0.036 \pm 0.001$

$0.035 \pm 0.002$

0.186

Left Eye

$0.041 \pm 0.003$

$0.044 \pm 0.003$

$0.045 \pm 0.005$

0.238

Right Eye

$0.042 \pm 0.003$

$0.042 \pm 0.003$

$0.043 \pm 0.006$

0.833

expressed as mean \pm standard deviation. 


\section{Table 4 (on next page)}

Food consumption $(\mathrm{g})$ and water intake $(\mathrm{mL})$ by rats

Food consumption $(\mathrm{g})$ and water intake $(\mathrm{mL})$ by rats 
Table 4. Food consumption $(\mathrm{g})$ and water intake $(\mathrm{mL})$ by rats

\begin{tabular}{|c|c|c|c|c|c|}
\hline Week & Control & AA (300mg/kg) & $\mathrm{AA}(2000 \mathrm{mg} / \mathrm{kg})$ & $P$ value & Values \\
\hline Food intake & & & & \multirow{3}{*}{0.884} & \\
\hline Week 1 & $140.14 \pm 2.193$ & $140.14 \pm 1.069$ & $139.57 \pm 1.272$ & & d as \\
\hline $\begin{array}{c}\text { Week } 2 \\
\text { Water intake }\end{array}$ & $140.00 \pm 1.290$ & $139.85 \pm 1.345$ & $139.57 \pm 2.225$ & & $\begin{array}{l}\text { standard } \\
\text { deviatio }\end{array}$ \\
\hline Week 1 & $213.00 \pm 18.248$ & $185.00 \pm 25.658$ & $193.85 \pm 23.891$ & \multirow{2}{*}{0.108} & n. \\
\hline Week 2 & $180.00 \pm 36.968$ & $162.85 \pm 28.263$ & $198.57 \pm 48.795$ & & \\
\hline
\end{tabular}


Table 5 (on next page)

Hematological profile of rats

Hematological profile of rats 
Table 5. Hematological profile of rats

\begin{tabular}{|c|c|c|c|c|c|}
\hline $\begin{array}{c}\text { Hematological } \\
\text { parameters }\end{array}$ & Control & AA (300mg/kg) & AA (2000 mg/kg) & $P$ value & $\begin{array}{l}\text { Values } \\
\text { express }\end{array}$ \\
\hline $\operatorname{RBCs}\left(10^{12} / \mathrm{L}\right)$ & $7.40 \pm 0.275$ & $7.30 \pm 0.894$ & $7.58 \pm 0.407$ & 0.706 & $\begin{array}{l}\text { mean } \pm \\
\text { standar }\end{array}$ \\
\hline $\mathrm{Hb}(\mathrm{g} / \mathrm{dL})$ & $12.73 \pm 0.937$ & $13.21 \pm 1.738$ & $13.68 \pm 0.495$ & 0.398 & $\begin{array}{l}\mathrm{d} \\
\text { deviatio }\end{array}$ \\
\hline WBCs $\left(10^{9} / \mathrm{L}\right)$ & $3.45 \pm 0.361$ & $3.03 \pm 0.382$ & $3.10 \pm 0.352$ & 0.140 & $\mathrm{n}$. \\
\hline Platelets $\left(10^{9} / \mathrm{L}\right)$ & $1001.66 \pm 4.082$ & $1003.33 \pm 5.163$ & $1003.33 \pm 5.163$ & 0.791 & \\
\hline Neutrophils (\%) & $17.16 \pm 1.471$ & $23.00 \pm 8.876$ & $26.00 \pm 4.732$ & 0.056 & \\
\hline Lymphocytes (\%) & $76.33 \pm 7.339$ & $68.50 \pm 9.974$ & $67.16 \pm 5.913$ & 0.130 & \\
\hline Monocytes (\%) & $3.83 \pm 0.752$ & $4.66 \pm 2.804$ & $4.66 \pm 0.816$ & 0.641 & \\
\hline Eosinophils (\%) & $3.33 \pm 0.816$ & $4.00 \pm 1.264$ & $2.66 \pm 1.211$ & 0.152 & \\
\hline PCV $(\mathrm{HCT} \%)$ & $34.00 \pm 0.894$ & $34.06 \pm 1.169$ & $34.00 \pm 1.264$ & 0.957 & \\
\hline MCV (fL) & $58.00 \pm 2.607$ & $59.00 \pm 1.549$ & $60.66 \pm 3.614$ & 0.262 & \\
\hline $\mathrm{MCH}(\mathrm{pg})$ & $17.88 \pm 0.228$ & $17.83 \pm 0.408$ & $17.50 \pm 0.547$ & 0.288 & \\
\hline $\operatorname{MCHC}(\mathrm{g} / \mathrm{dL})$ & $30.16 \pm 0.408$ & $30.33 \pm 0.516$ & $30.16 \pm 0.408$ & 0.761 & \\
\hline
\end{tabular}


Table 6(on next page)

Biochemical profile of rats

Biochemical profile of rats 
1

2

3

4

5

6

8

9

10

11

12

13

14

15

16

17

18

19 20

21

22

23

24

25

26

27

28

29

30
Table 6. Biochemical profile of rats

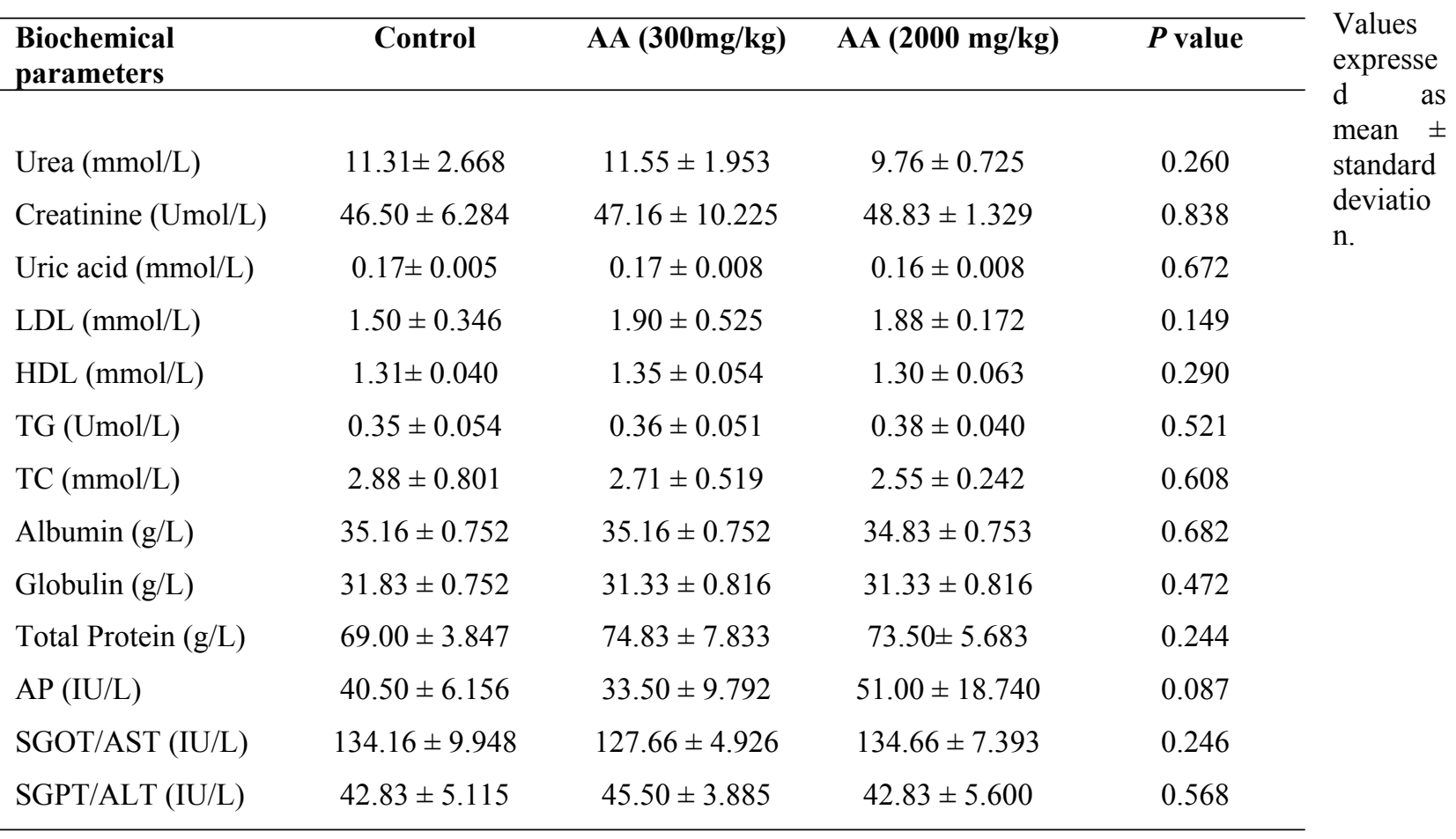


Figure 1

\title{
Graphical abstract
}

Graphical abstract

\author{
Graphical abstract
}

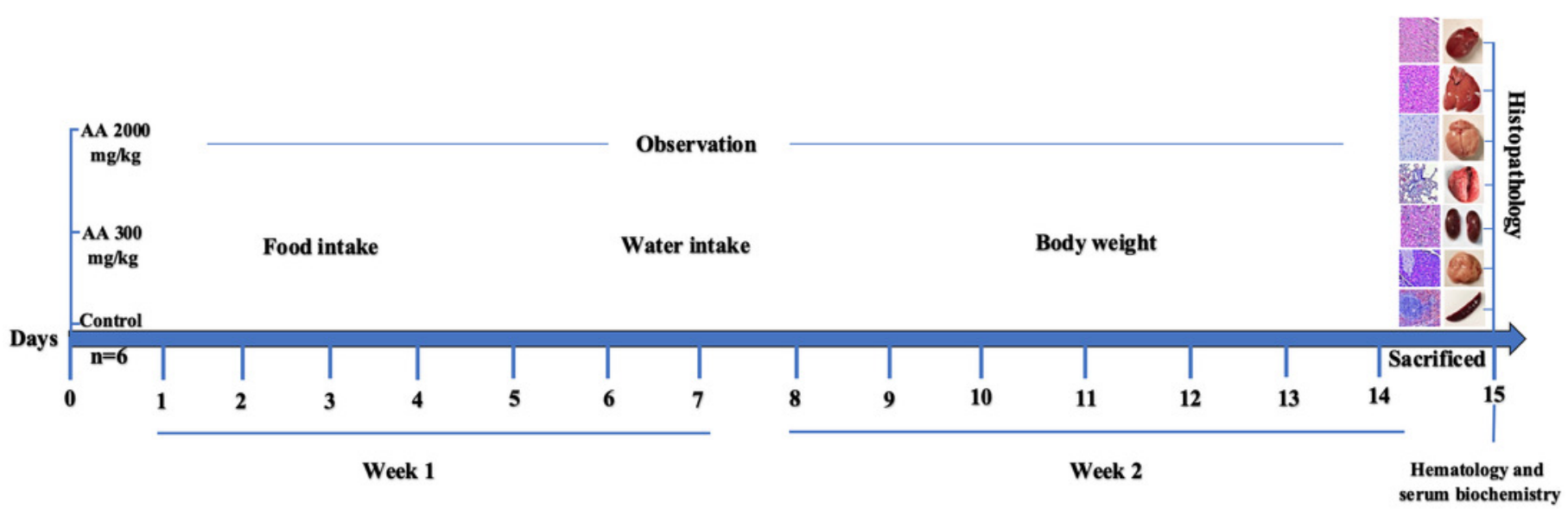


Figure 2

Schematic diagram representing isolation of Arjunolic acid (AA).

Schematic diagram representing isolation of Arjunolic acid (AA). Ethyl acetate (EtOAc), Petroleum ether (Pet Ether), Methyl alcohol ( $\mathrm{MeOH})$, Acetic acid ( $\mathrm{AcOH})$, Thin layer chromatography (TLC), Fraction (fr), Nuclear magnetic resonance (NMR). 


\section{Termminalia arjuna bark}

$(3.0 \mathrm{~kg})$

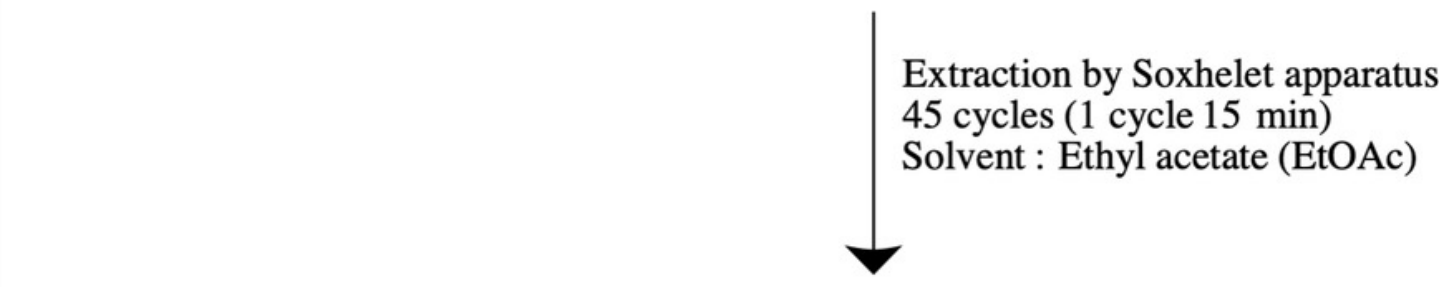

\section{Extract 53.5 g}

Si-gel open column chromatography

Dimension : $4.0 \times 100 \mathrm{~cm}$

Solvent : Petrolium ether - EtOAc step gradient

\begin{tabular}{|l|l|l|l|c|c|}
\hline Pet Ether & $\downarrow$ & & & $\begin{array}{c}\text { Pet Ether: EtOAc } \\
1: 1\end{array}$ & $\begin{array}{c}\text { EtOAc: : MeOH: AcOH } \\
9.0: 1.0: 0.1\end{array}$ \\
& $\downarrow$
\end{tabular}

fr. 1

fr. 1

fr. 16

fr. 86

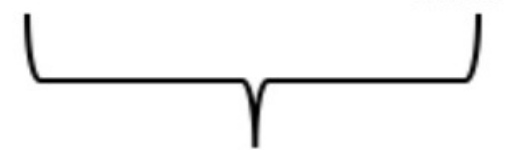

fr. 13

$3.9 \mathrm{~g}$

Combined based on si-gel

TLC monitoring

Solvent system $\mathrm{CHCl}_{3}: \mathrm{MeOH}$

Repeated Crystalization of fr.7 to fr.9 with EtOAc

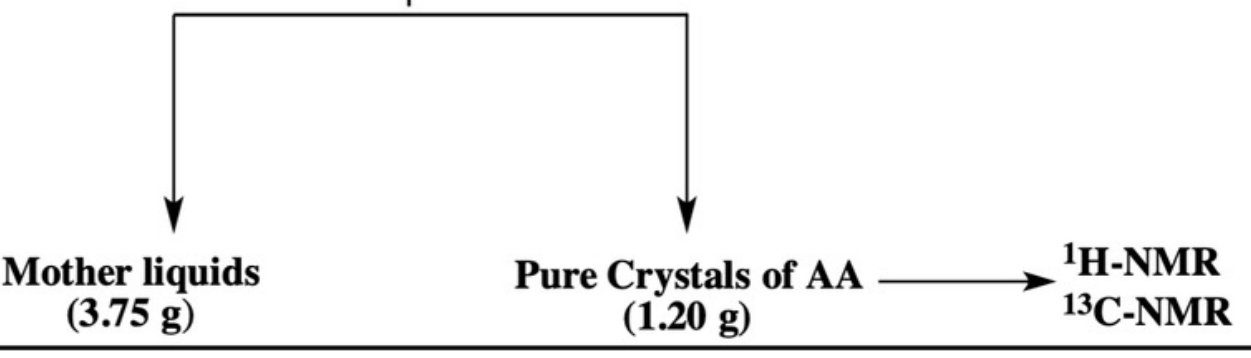


Figure 3

Macroscopic photographs of harvested organs

Macroscopic photographs showing normal morphology of heart $(A, B, C)$, liver $(D, E, F)$, brain $(\mathrm{G}, \mathrm{H}, \mathrm{I})$ and lungs $(\mathrm{J}, \mathrm{K}, \mathrm{L})$ from female SD rats
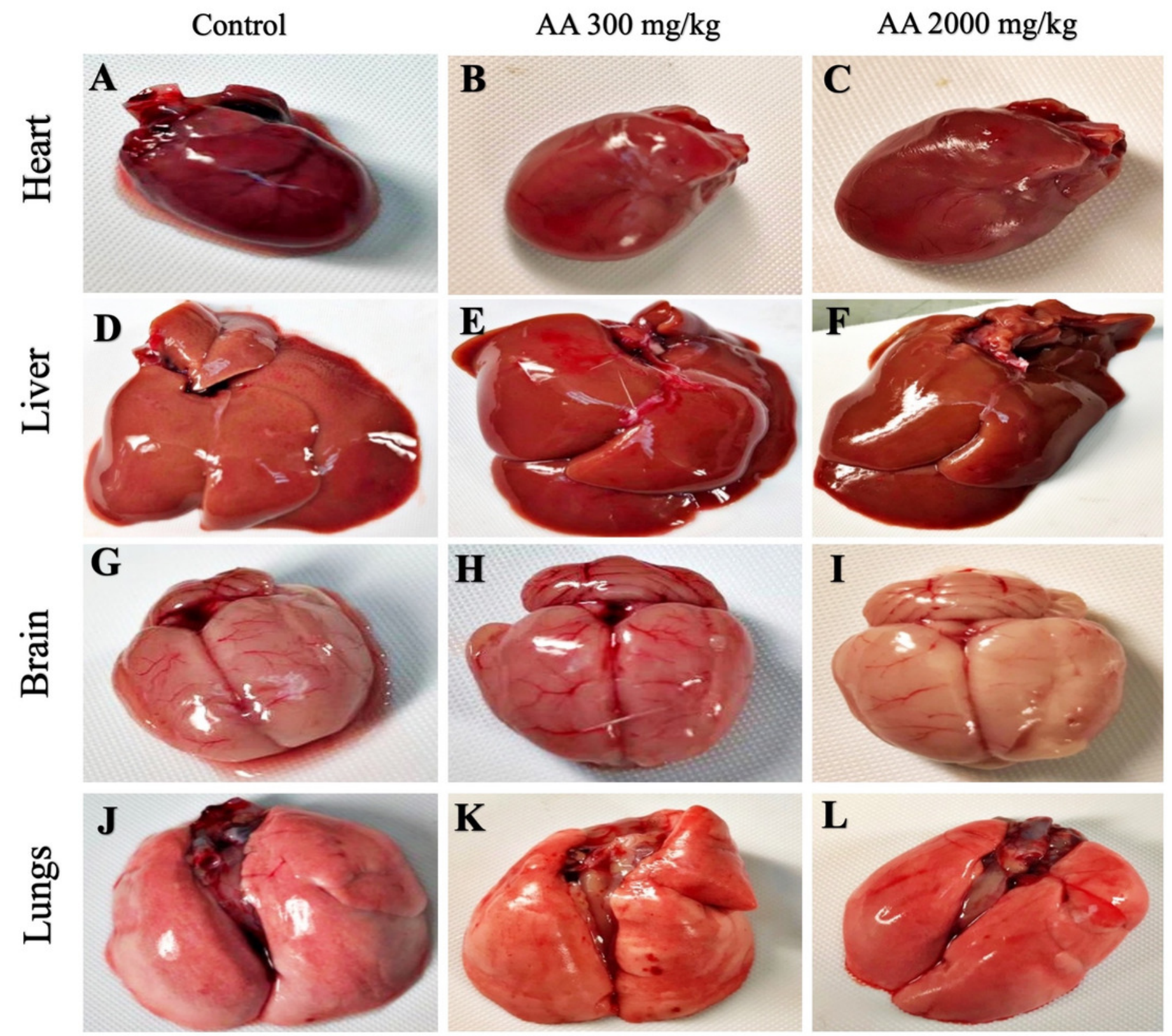


\section{Figure 4}

Macroscopic photographs of harvested organs

Macroscopic photographs showing normal morphology of kidney $(A, B, C)$, pancreas $(D, E, F)$ and spleen $(\mathrm{G}, \mathrm{H}, \mathrm{I})$ from female SD rats
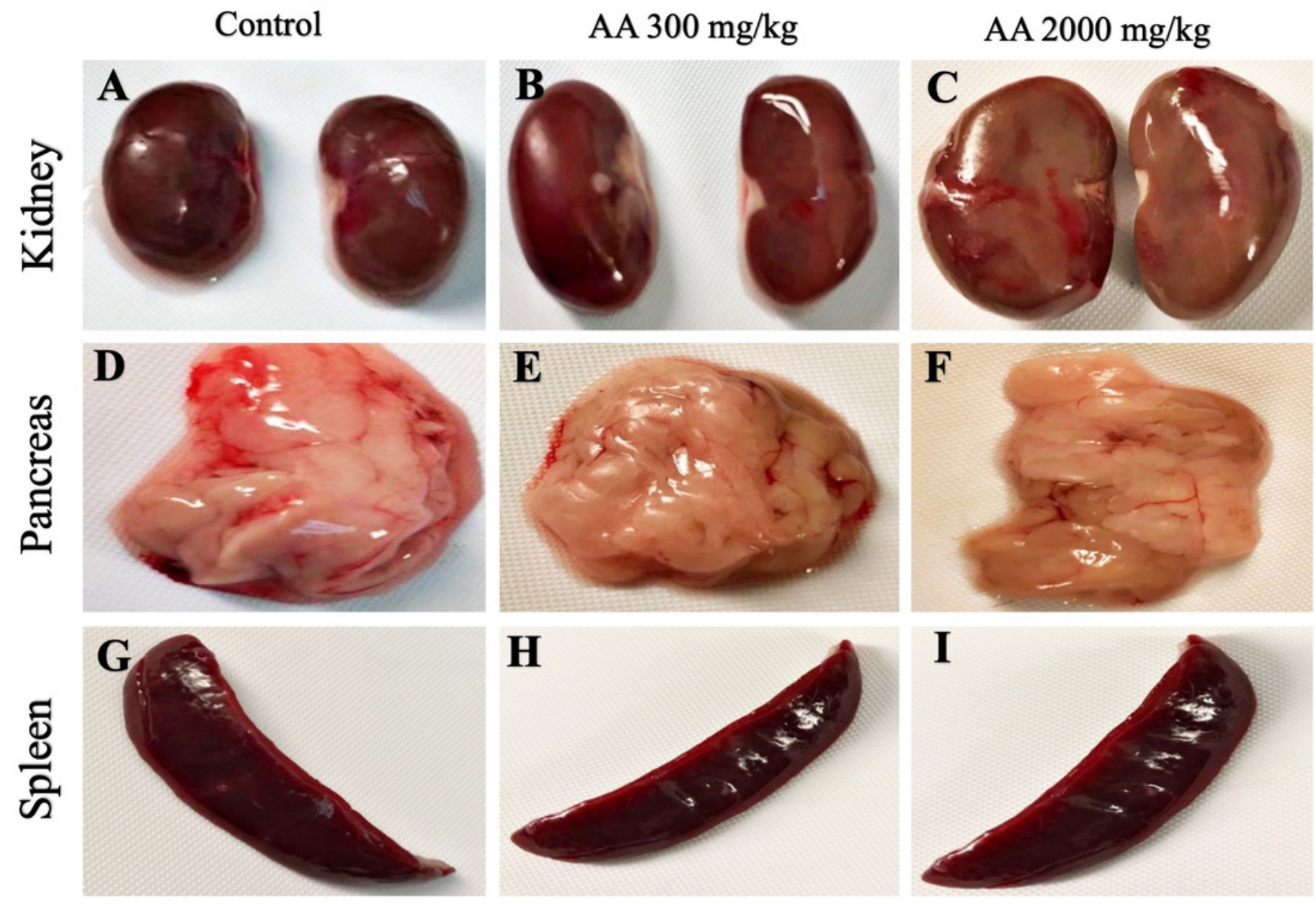


\section{Figure 5}

Photomicrographs of vital organs displaying H\&E staining of heart, liver, brain and lungs

Photomicrographs of vital organs displaying normal architecture of heart $(A, B, C)$, liver

$(D, E, F)$, brain $(G, H, I)$ and lungs $(J, K, L)$ after single oral dose of $A A(H \& E$ stain $\times 200)$.

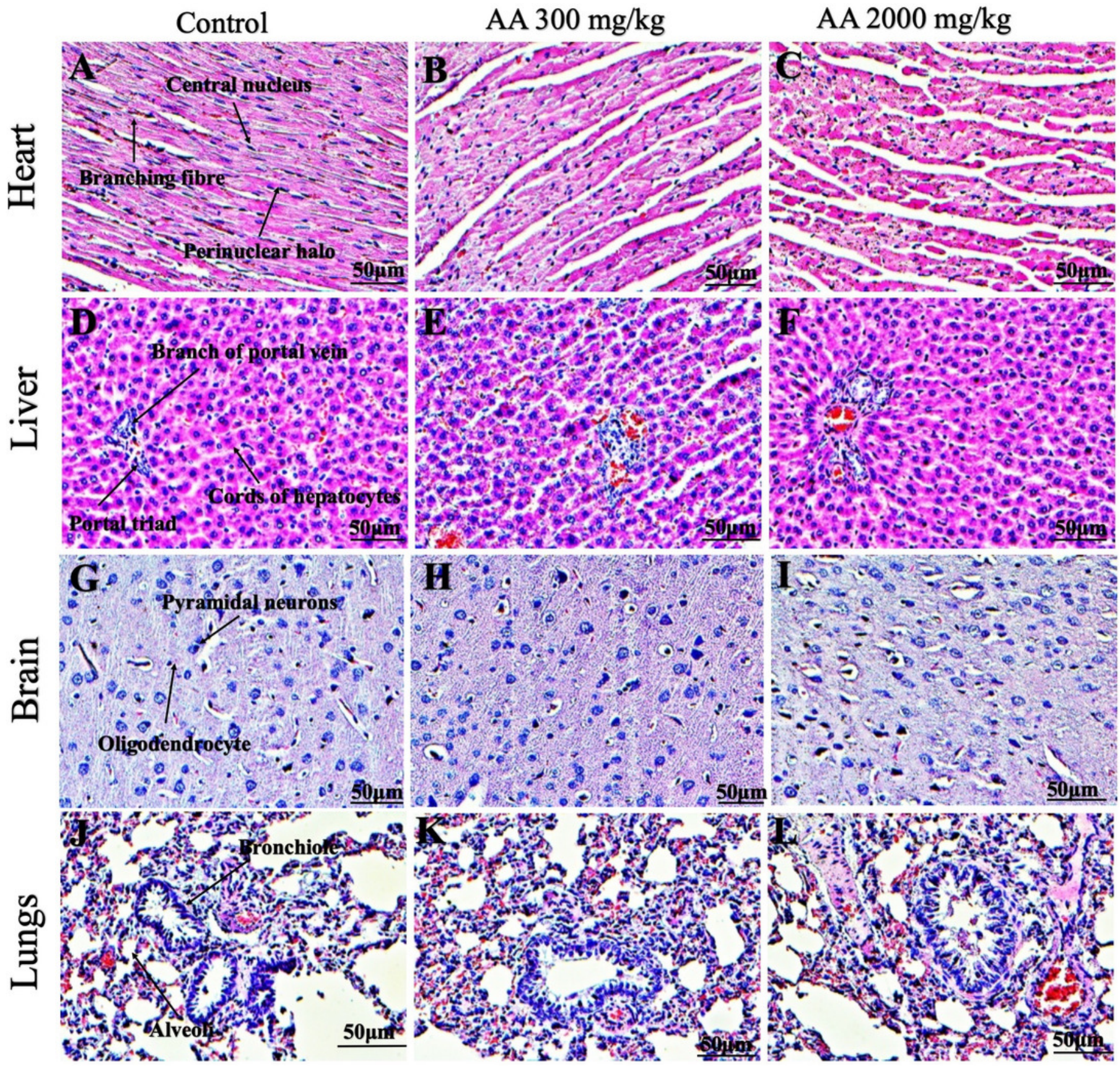




\section{Figure 6}

Photomicrographs of vital organs representing normal architecture of kidney, pancreas and spleen

Photomicrographs of vital organs displaying normal architecture of kidney $(A, B, C)$, pancreas $(D, E, F)$ and spleen $(G, H, I)$ after single oral dose of $A A(H \& E$ stain $\times 200)$. Proximal convoluted tubules (PCT), Distal convoluted tubules (DCT).

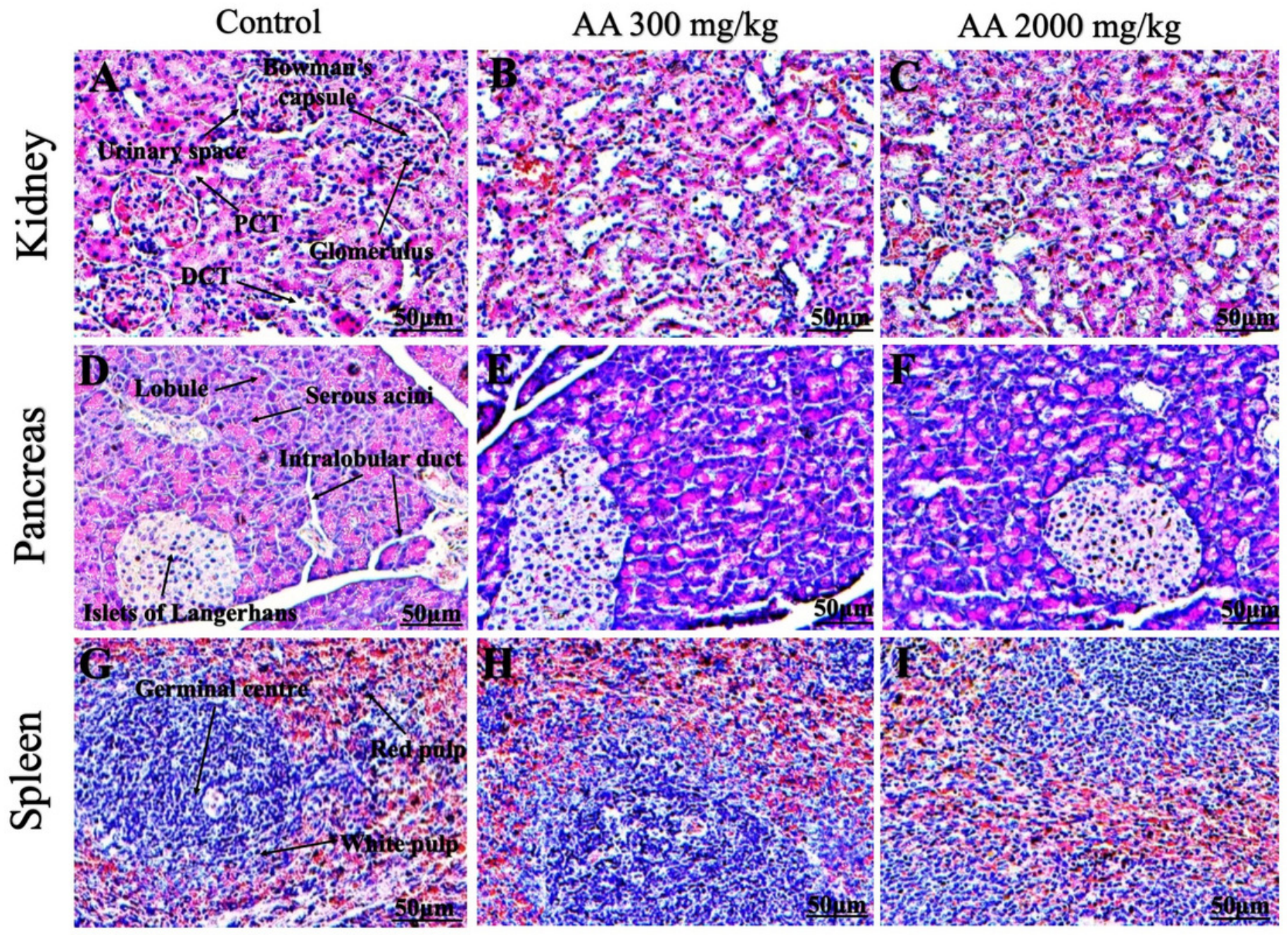




\section{Figure 7}

Photomicrographs of vital organs presenting Masson trichrome staining of heart, liver, brain and lungs,

Photomicrographs of vital organs presenting normal architecture of heart $(A, B, C)$, liver $(D, E, F)$, brain $(G, H, I)$ and lungs $(J, K, L)$ after a single oral dose of $A A$ (Masson trichrome stain, $x 200)$. 

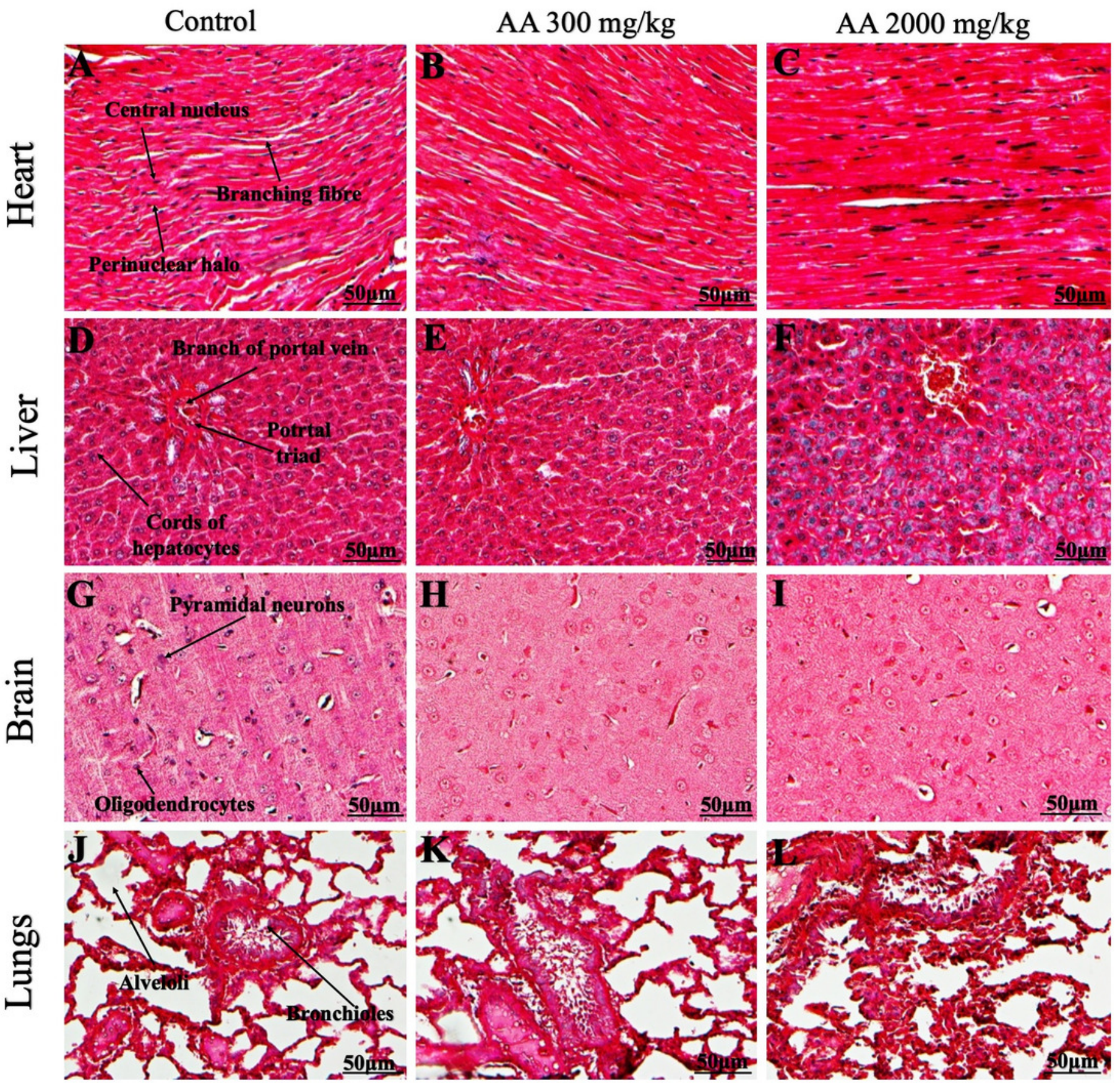


\section{Figure 8}

Photomicrographs of vital organs presenting Masson trichrome staining of kidneys, pancreas and spleen.

Photomicrographs of vital organs presenting normal architecture of kidneys $(A, B, C)$, pancreas $(D, E, F)$ and spleen $(G, H, I)$ after a single oral dose of AA (Masson trichrome stain, $x 200)$.

Proximal convoluted tubule (PCT), Distal convoluted tubule (DCT).
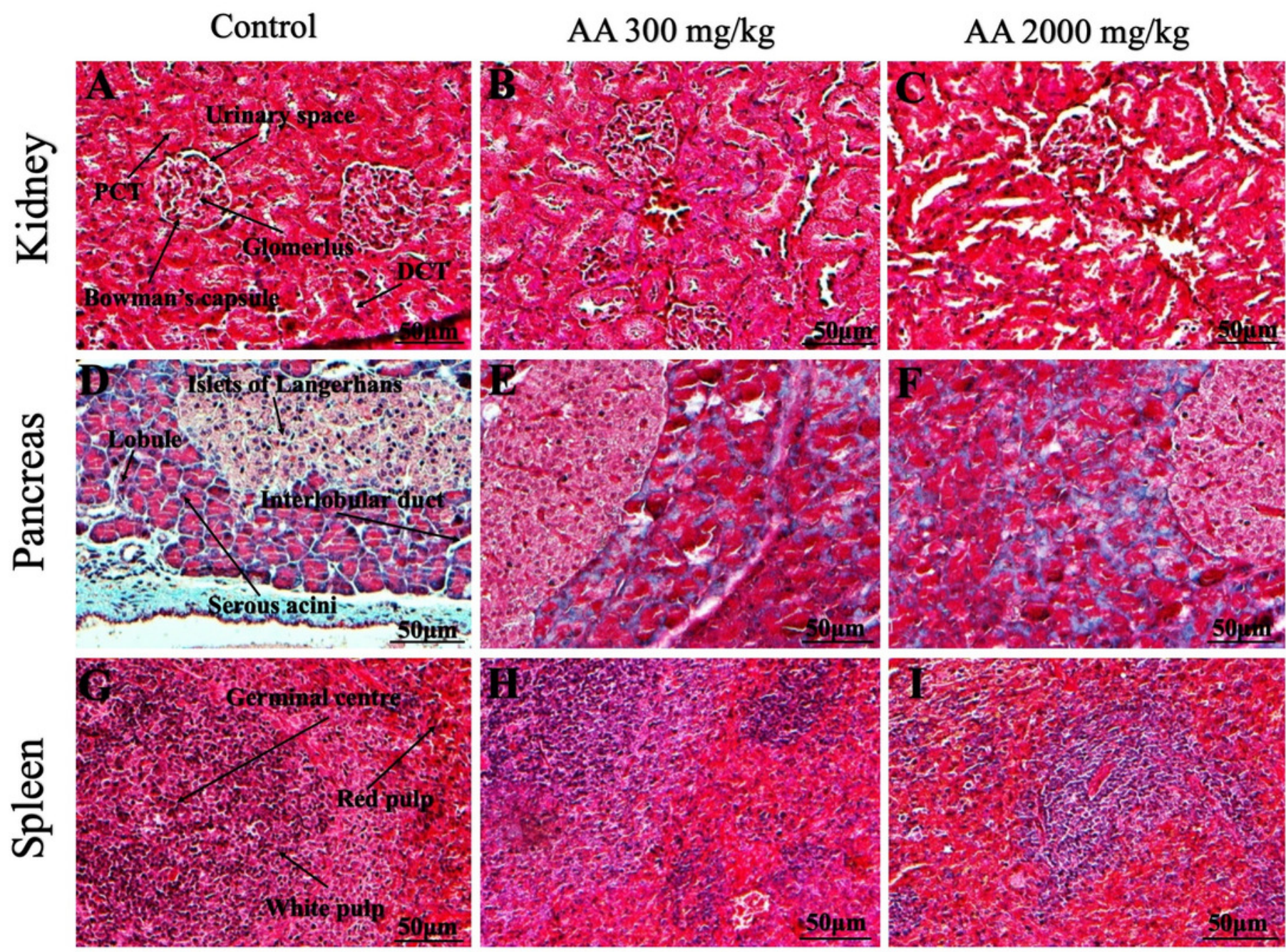
Figure 9

Photomicrographs of vital organs demonstrating Periodic acid Schiff staining of heart, liver, brain and lungs.

Photomicrographs of vital organs demonstrating normal architecture of heart $(A, B, C)$, liver $(\mathrm{D}, \mathrm{E}, \mathrm{F})$, brain $(\mathrm{G}, \mathrm{H}, \mathrm{I})$ and lungs $(\mathrm{J}, \mathrm{K}, \mathrm{L})$ after a single oral dose of AA (Periodic acid Schiff stain, $x 200)$. 

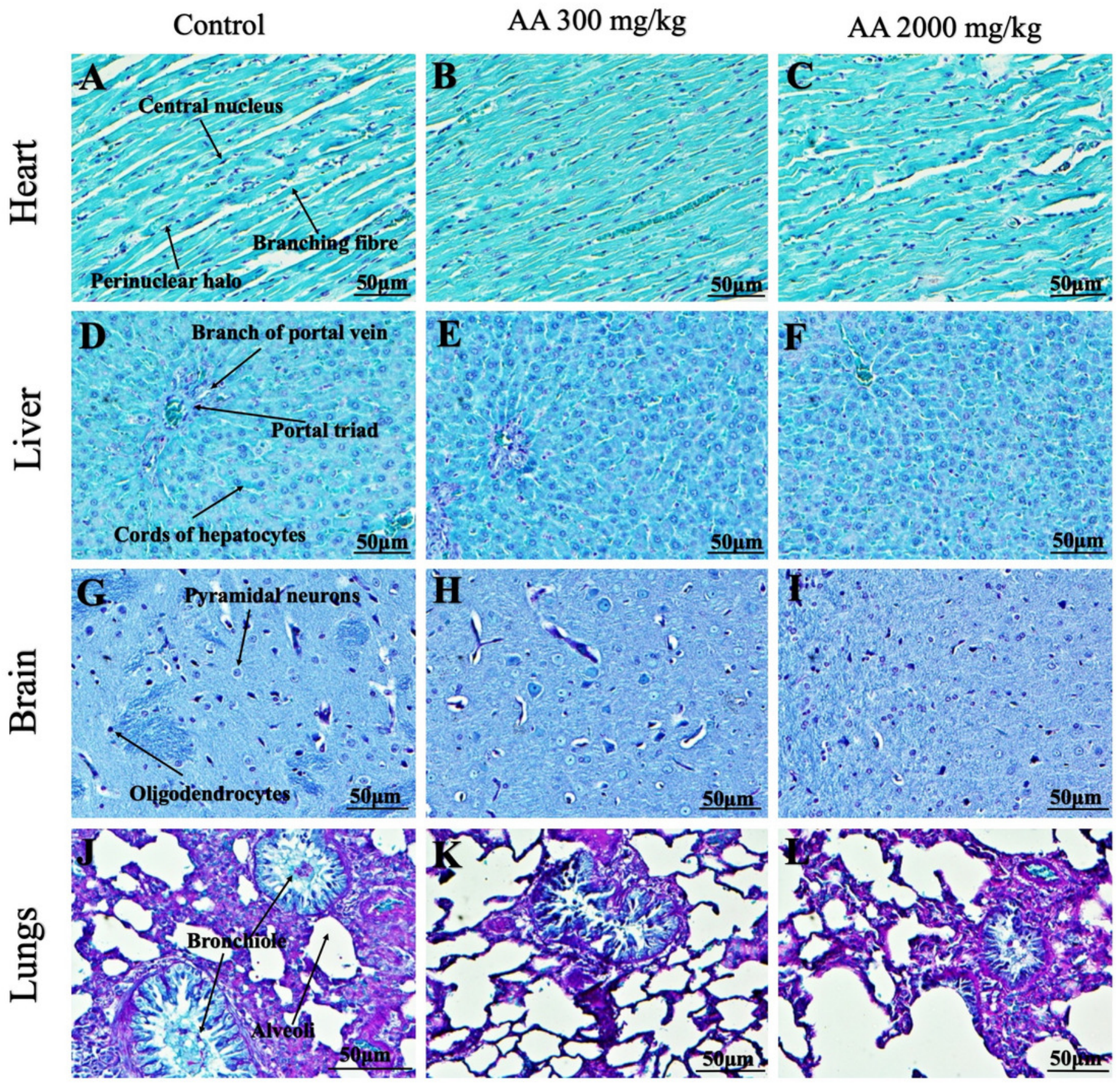


\section{Figure 10}

Photomicrographs of vital organs demonstrating Periodic acid Schiff staining of kidneys, pancreas and spleen

Photomicrographs of vital organs demonstrating normal architecture of kidneys $(A, B, C)$, pancreas $(D, E, F)$ and spleen $(G, H, I)$ after a single oral dose of $A A$ (Periodic acid Schiff stain, x200). Proximal convoluted tubule (PCT), Distal convoluted tubule (DCT).
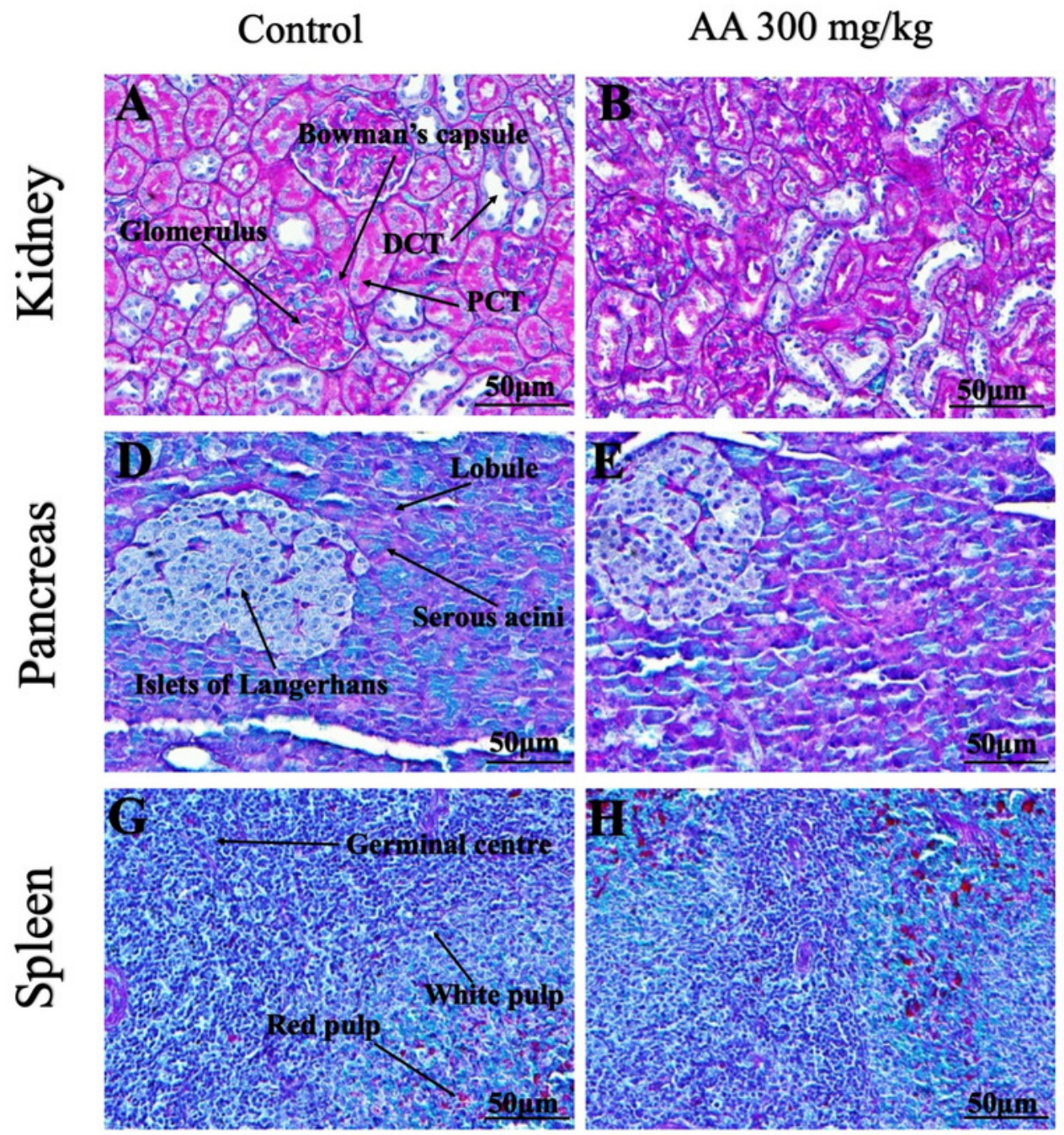

AA $2000 \mathrm{mg} / \mathrm{kg}$
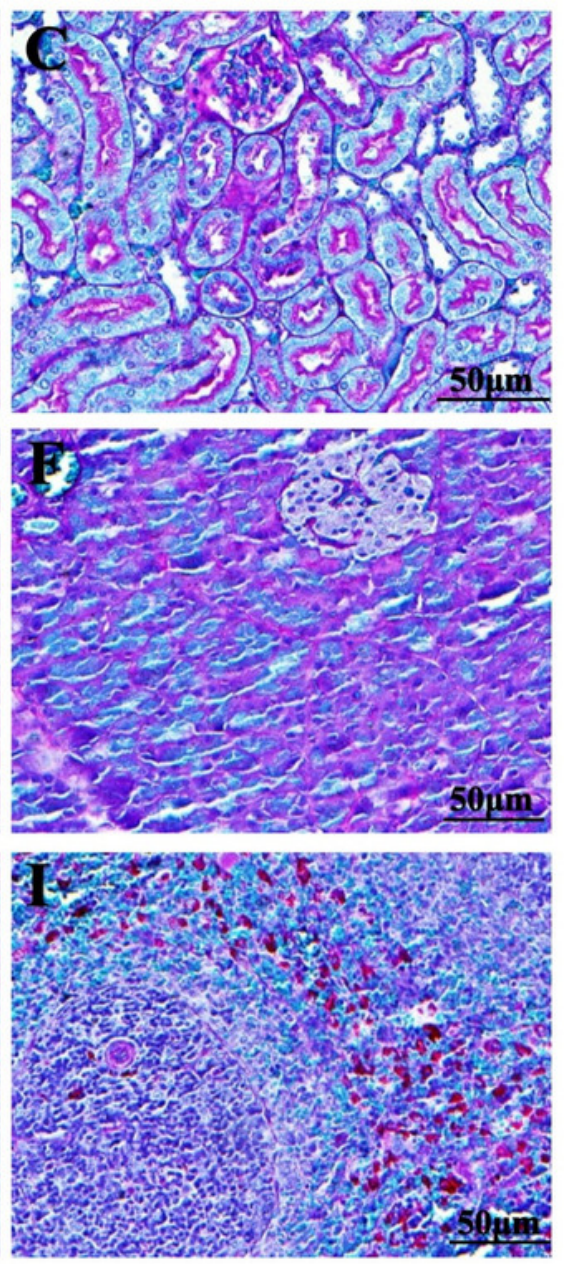
Figure 11

Photomicrographs of vital organs representing Oil O Red staining of heart, liver, brain and lungs

Photomicrographs of vital organs representing normal architecture of heart $(A, B, C)$, liver $(D, E, F)$, brain $(G, H, I)$ and lungs $(J, K, L)$ after a single oral dose of AA (Oil O Red stain, $x 200$ ). 


\section{Control}
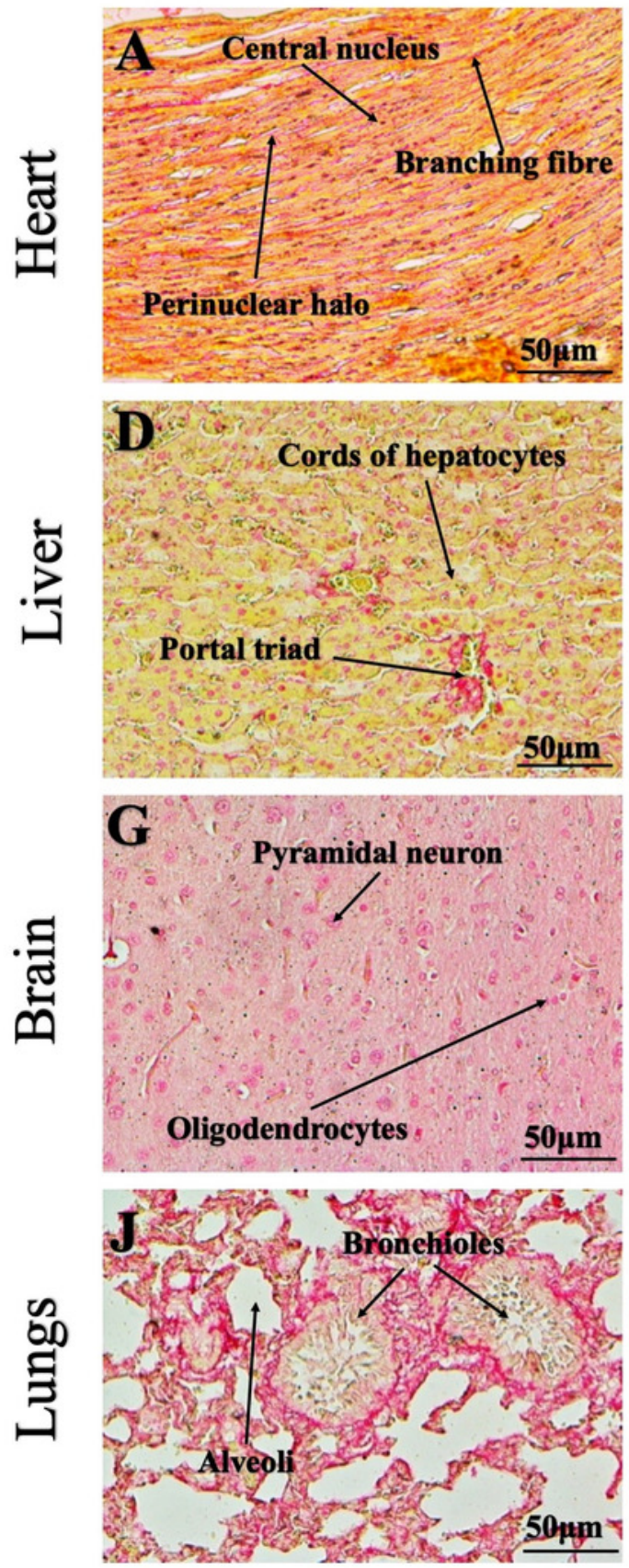

AA $300 \mathrm{mg} / \mathrm{kg}$
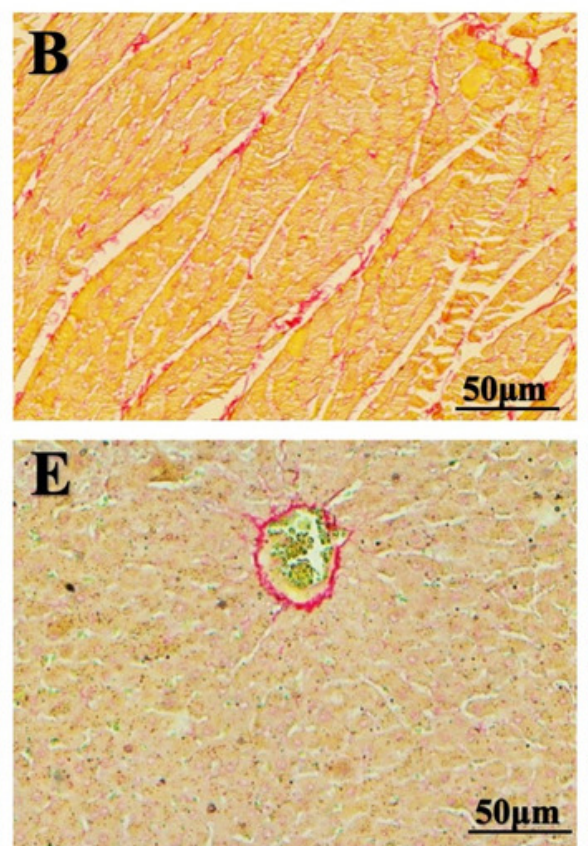

H

$50 \mu \mathrm{m}$

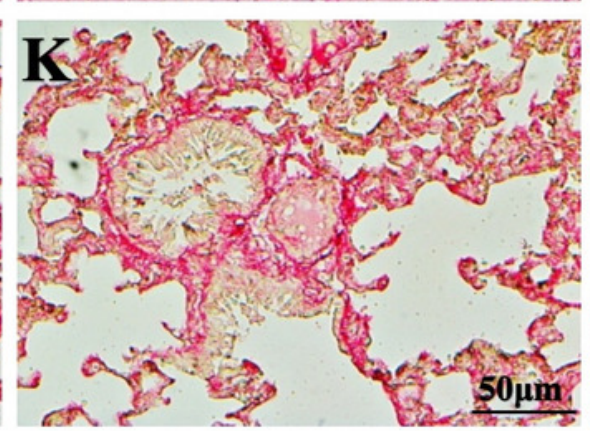

AA $2000 \mathrm{mg} / \mathrm{kg}$
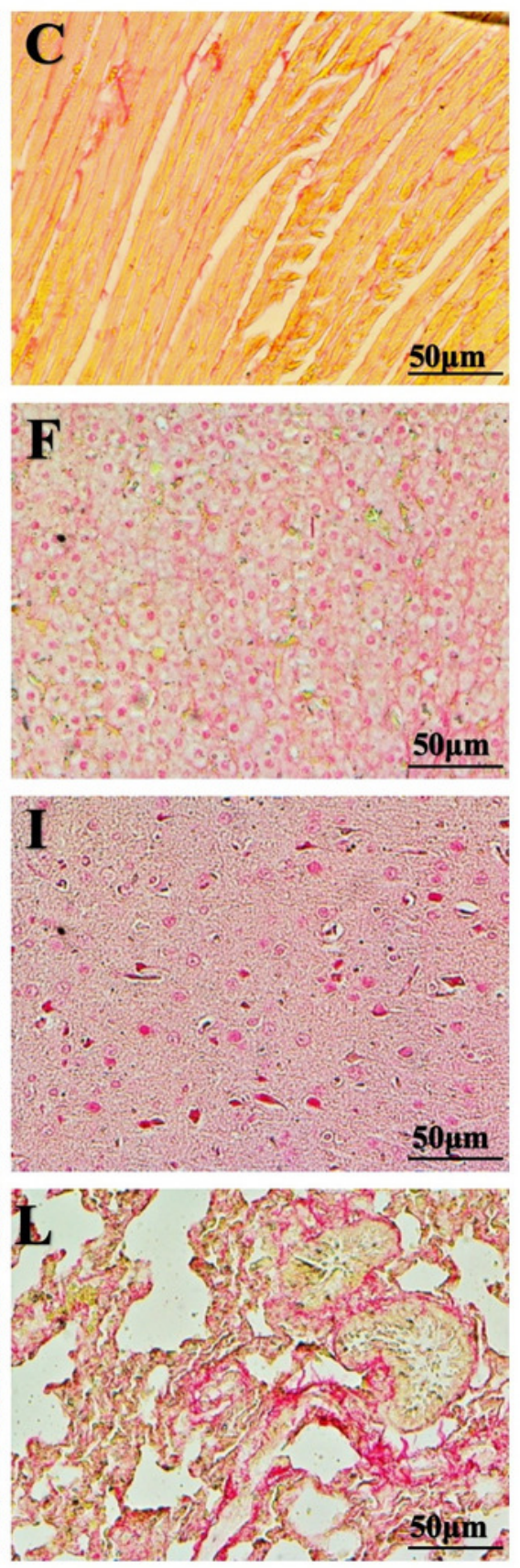


\section{Figure 12}

Photomicrographs of vital organs representing Oil O Red staining of kidneys, pancreas and spleen

Photomicrographs of vital organs representing normal architecture of kidneys $(A, B, C)$, pancreas (D,E,F) and spleen ( $G, H, I)$ after a single oral dose of AA (Oil O Red stain, $x 200)$. Proximal convoluted tubule (PCT), Distal convoluted tubule (DCT).
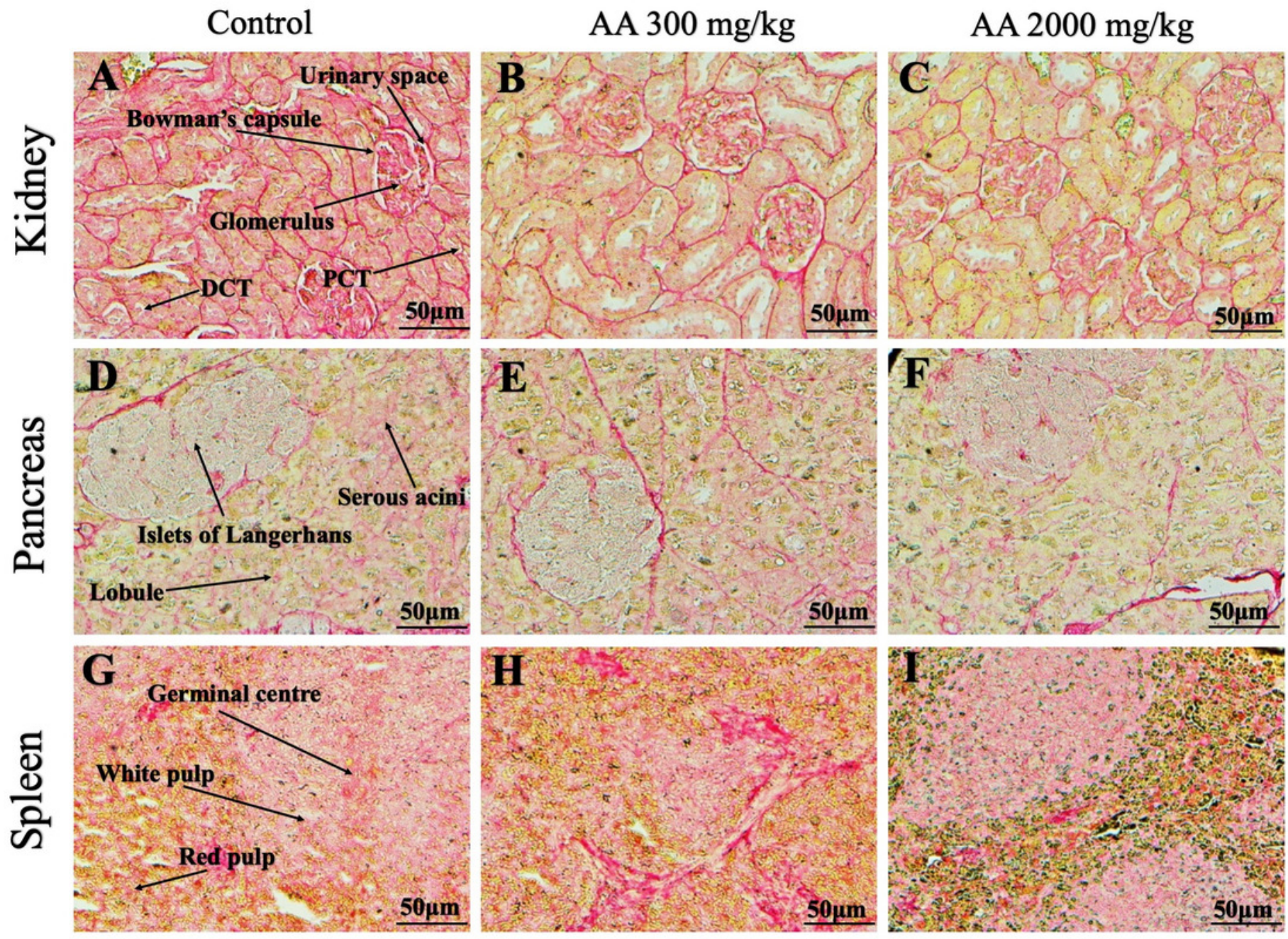